\title{
Effect of DC Link Control Strategies on Multiterminal AC-DC Power Flow
}

\author{
Shagufta Khan and Suman Bhowmick \\ Department of Electrical Engineering, Delhi Technological University, Delhi 110042, India \\ Correspondence should be addressed to Shagufta Khan; khan.shagufta7@gmail.com
}

Received 20 September 2014; Accepted 18 March 2015

Academic Editor: George E. Tsekouras

Copyright (C) 2015 S. Khan and S. Bhowmick. This is an open access article distributed under the Creative Commons Attribution License, which permits unrestricted use, distribution, and reproduction in any medium, provided the original work is properly cited.

\begin{abstract}
For power-flow solution of power systems incorporating multiterminal DC (MTDC) network(s), five quantities are required to be solved per converter. On the other hand, only three independent equations comprising two basic converter equations and one DC network equation exist per converter. Thus, for solution, two additional equations are required. These two equations are derived from the control specifications adopted for the DC links. Depending on the application, several combinations of valid control specifications are possible. Each combination of a set of valid control specifications is known as a control strategy. The number of control strategies increases with an increase in the number of the DC terminals or converters. It is observed that the power-flow convergence of integrated AC-MTDC power systems is strongly affected by the control strategy adopted for the DC links. This work investigates the mechanism by which different control strategies affect the power-flow convergence pattern of AC-MTDC power systems. To solve the DC variables in the Newton-Raphson (NR) power-flow model, sequential method is considered in this paper. Numerous case studies carried out on a three-terminal DC network incorporated in the IEEE-300 bus test system validate this.
\end{abstract}

\section{Introduction}

Multiterminal DC (MTDC) systems have been proven to be more versatile on account of their ability to fully exploit the economic and technical advantages of HVDC technology. Since the success of the first MTDC system "SardiniaCorsica-Italy Scheme" in 1991, the application of MTDC systems has shown a steady increase. Further, with the rapid progress of renewable energy sources and offshore wind farms, MTDC applications are increasing. MTDC transmits bulk power from several generating stations to several load centres. It is more flexible and economical, being capable of connecting more than two asynchronous AC systems [1-4].

Now, for planning, operation, and control of power systems incorporated with MTDC links, power-flow solution of such systems is required. Power-flow solution of integrated AC-MTDC systems requires five quantities to be solved per converter. These include the DC voltage, the DC current, the control angle, the converter transformer tap ratio, and the converter power factor. On the other hand, only three independent equations comprising two basic converter equations and one DC network equation exist per converter. Thus, for solution, two additional equations are usually required. These two equations are derived from the control specifications adopted for the DC links. Thus, mathematically, the control specifications are used to bridge the gap between the number of independent equations and the number of unknown quantities. Control specifications usually include specified values of converter transformer tap ratio, converter control angle, DC voltage, DC current, or DC power. Depending on the application, several combinations of valid control specifications are possible. Each combination of a set of valid control specifications is known as a control strategy. The number of possible control strategies increases drastically with increase in the number of the DC terminals or converters. Out of a myriad of combinations, only some control strategies are practically adopted in practice.

To carry out power flow in AC-MTDC systems, two different algorithms have generally been reported in the literature. These are known as the unified and the sequential method, respectively. Some excellent research works on the unified and the sequential power-flow method are presented in [5-19]. Unlike the unified method, the sequential method is easier to implement and poses lesser computational burden 


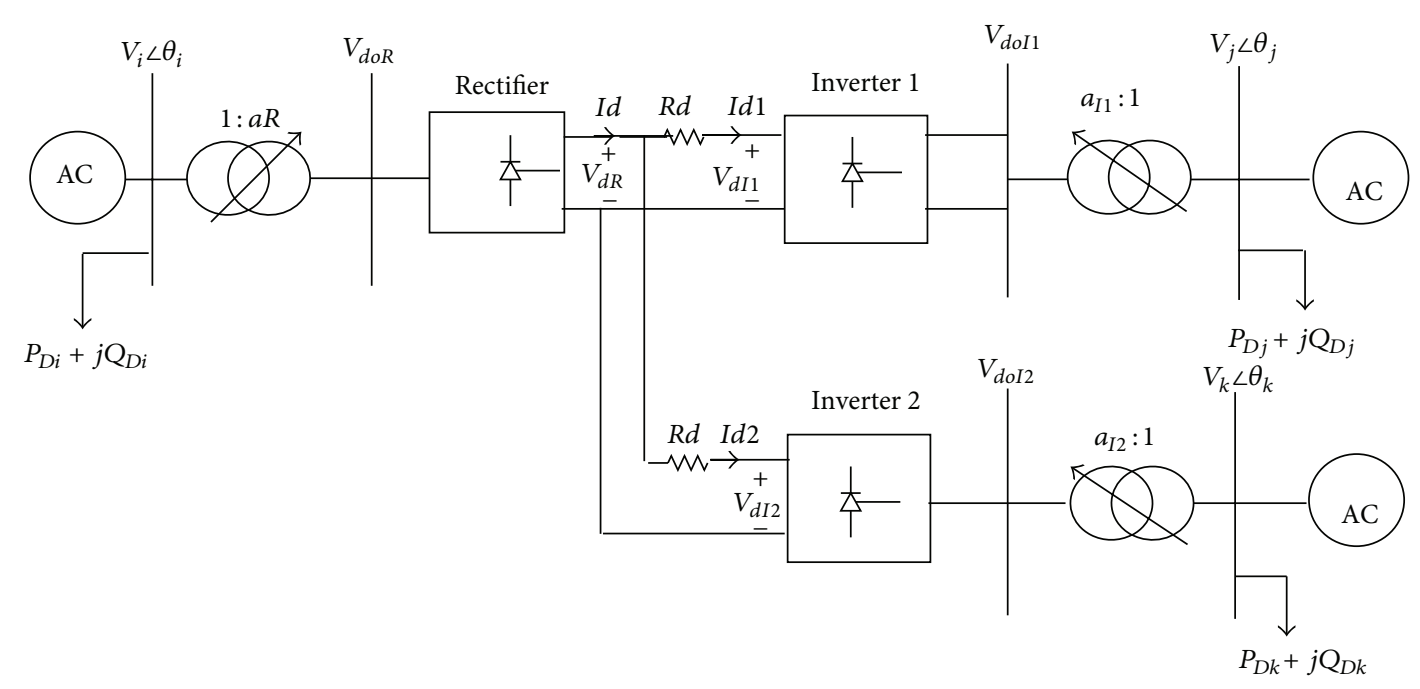

FIGURE 1: Three-terminal HVDC link between buses “ $i$," “ $j$," and “ $k$ ” of an existing power system network.

due to the smaller size of the Jacobian matrix. Consequently, in this work, only the sequential AC-DC power-flow algorithm has been considered.

In the sequential AC-DC power-flow algorithm, the $\mathrm{AC}$ and DC systems are solved separately in each iteration and are coupled by injecting an equivalent amount of real and reactive power at the terminal AC buses. It is observed that each different control strategy affects the sequential power-flow convergence in a uniquely different manner. For standard control strategies, that is, constant DC voltage or current or power, the convergence rate can be improved by solving the DC and AC systems independently. On the other hand, for nonstandard ones like constant tap ratios and constant terminal voltage, the convergence may suffer. The mechanism by which this occurs has not been very clear and has not been exclusively addressed in the literature. This motivated the authors to investigate how different control strategies affect the power-flow convergence. The work is validated by numerous case studies carried out on a three-terminal DC network incorporated in the IEEE 300-bus test system. Although a large number of control strategies are possible with the three-terminal DC network, however, due to a lack of space, only results corresponding to nine different control strategies are reported here.

This paper is arranged as follows: in Section 2, the mathematical modelling of the AC-MTDC system is presented. Section 3 details a few of the control strategies possible for a three-terminal DC network. In Section 4, the AC-MTDC power-flow equations are presented, with the DC link powers acting as an equivalent load on the converter AC buses. Section 5 details the case studies carried out with a threeterminal DC network incorporated in the IEEE 300-bus test system. The conclusions are presented in Section 6.

\section{AC-MTDC System Modelling}

Figure 1 shows a typical AC power system incorporating a three-terminal DC network. The DC network contains two HVDC links. The first link is connected in the branch " $i$ - $j$ " between any two system buses " $i$ " and " $j$ " of the network while the second one is connected in the branch " $i$ - $k$ " between system buses " $i$ " and " $k$." The three converters representing one rectifier and two inverters are connected to the AC system at buses " $i$," “ $j$," and " $k$," respectively, through their respective converter transformers. The effect of the DC links is accounted for as equivalent amount of real and reactive power injections $P_{d R}, Q_{d R}, P_{d I 1}, Q_{d I 1}, P_{d I 2}$, and $Q_{d I 2}$ at the converters' AC terminal buses " $i$," " $j$," and " $k$," respectively. Although these power injections are not shown in Figure 1, they are included in the analysis by appropriate modifications of the power-flow equations as detailed later in Section 4.

Prior to the selection of variables and formulation of the equations, several basic assumptions are required which are generally accepted in the analysis of steady state DC converter operation [1-4]. These are as follows.

(1) The three AC voltages at the terminal bus bars are balanced and sinusoidal.

(2) The operation of the converters is perfectly balanced.

(3) The direct currents and voltages are smooth.

(4) The converter transformers are lossless and their magnetizing admittances are ignored.

Subsequently, the DC and AC equations are combined together which requires the translation of the converter equations into the per-unit system in order to use them with AC system per-unit equations. The base values for the DC system are defined as the following.

Selection of base values for the DC system:

$$
\begin{gathered}
V_{\mathrm{dc} \text { base }}=k V_{\mathrm{ac} \text { base }} ; \quad \text { where } k=\frac{3 \sqrt{2}}{\pi} n_{b}, \\
I_{\mathrm{dc} \text { base }}=\frac{\sqrt{3}}{k} I_{\mathrm{ac} \text { base }}
\end{gathered}
$$


TABLE 1: Some control strategies for a 3-terminal DC link.

\begin{tabular}{lccc}
\hline \multirow{2}{*}{ Control strategies } & \multicolumn{2}{c}{ Specified quantities } & Unknown quantities \\
& Included in DC load flow & Excluded in DC load flow & \\
\hline 1 & $P_{d I 1}, P_{d I 2}, V_{d R}$ & $\alpha_{R}, \gamma_{I 1}, \gamma_{I 2}$ & $V_{d I 1}, V_{d I 2}, P_{d R}, I_{d I 1}, I_{d I 2}, I_{d R}, a_{R}, a_{I 1}, a_{I 2}, \cos \phi_{R}, \cos \phi_{I 1}, \cos \phi_{I 2}$ \\
3 & $P_{d I 1}, I_{d I 2}, V_{d R}$ & $\alpha_{R}, \gamma_{I 1}, \gamma_{I 2}$ & $V_{d I 1}, V_{d I 2}, P_{d I 2}, P_{d R}, I_{d I 1}, I_{d R}, a_{R}, a_{I 1}, a_{I 2}, \cos \phi_{R}, \cos \phi_{I 1}, \cos \phi_{I 2}$ \\
4 & $P_{d I 2}, I_{d I 1}, V_{d R}$ & $\alpha_{R}, \gamma_{I 1}, \gamma_{I 2}$ & $V_{d I 1}, V_{d I 2}, P_{d I 1}, P_{d R}, I_{d I 2}, I_{d R}, a_{R}, a_{I 1}, a_{I 2}, \cos \phi_{R}, \cos \phi_{I 1}, \cos \phi_{I 2}$ \\
5 & $I_{d I 1}, I_{d I 2}, V_{d R}$ & $\alpha_{R}, \gamma_{I 1}, \gamma_{I 2}$ & $V_{d I 1}, V_{d I 2}, P_{d I 1}, P_{d I 2}, P_{d R}, I_{d R}, a_{R}, a_{I 1}, a_{I 2}, \cos \phi_{R}, \cos \phi_{I 1}, \cos \phi_{I 2}$ \\
6 & $P_{d I 1}, P_{d I 2}, V_{d R}$ & $a_{R}, a_{I 1}, a_{I 2}$ & $V_{d I 1}, V_{d I 2}, P_{d R}, I_{d I 1}, I_{d I 2}, I_{d R}, a_{R}, a_{I 1}, a_{I 2}, \cos \phi_{R}, \cos \phi_{I 1}, \cos \phi_{I 2}$ \\
7 & $I_{d I 1}, I_{d I 2}, V_{d R}$ & $a_{R}, a_{I 1}, a_{I 2}$ & $V_{d I 1}, V_{d I 2}, P_{d I 1}, P_{d I 2}, P_{d R}, I_{d R}, a_{R}, a_{I 1}, a_{I 2}, \cos \phi_{R}, \cos \phi_{I 1}, \cos \phi_{I 2}$ \\
8 & $P_{d I 1}, I_{d I 2}, V_{d R}$ & $a_{R}, a_{I 1}, a_{I 2}$ & $V_{d I 1}, V_{d I 2}, P_{d I 2}, P_{d R}, I_{d I 1}, I_{d R}, a_{R}, a_{I 1}, a_{I 2}, \cos \phi_{R}, \cos \phi_{I 1}, \cos \phi_{I 2}$ \\
9 & $I_{d I 1}, P_{d I 2}, V_{d R}$ & $a_{R}, a_{I 1}, a_{I 2}$ & $V_{d I 1}, V_{d I 2}, P_{d I 1}, P_{d R}, I_{d I 2}, I_{d R}, a_{R}, a_{I 1}, a_{I 2}, \cos \phi_{R}, \cos \phi_{I 1}, \cos \phi_{I 2}$ \\
& $P_{d I 1}, P_{d I 2}, V_{d I 1}$ & $\alpha_{R}, \gamma_{I 1}, \gamma_{I 2}$ & $V_{d I R}, V_{d I 2}, P_{d R}, I_{d I 1}, I_{d I 2}, I_{d R}, a_{R}, a_{I 1}, a_{I 2}, \cos \phi_{R}, \cos \phi_{I 1}, \cos \phi_{I 2}$ \\
\hline
\end{tabular}

$$
\begin{aligned}
& Z_{\mathrm{dc} \text { base }}=k^{2} Z_{\mathrm{ac} \mathrm{base}} \\
& R_{\mathrm{dc} \text { base }}=\frac{3}{\pi} n_{b} X_{c \text { base }}
\end{aligned}
$$

which culminate in the per-unit AC-DC system equations as given in the following.

Basic converter equations for a 3-terminal DC network in per-unit system:

$$
\begin{gathered}
V_{d R}=a_{R} V_{i} \cos \alpha_{R}-X_{c} I_{d R}, \\
V_{d I 1}=a_{I 1} V_{j} \cos \gamma_{I 1}-X_{c} I_{d I 1}, \\
V_{d I 2}=a_{I 2} V_{k} \cos \gamma_{I 2}-X_{c} I_{d I 2}, \\
V_{d R}=a_{R} V_{i} \cos \phi_{R}, \\
V_{d I 1}=a_{I 1} V_{j} \cos \phi_{I 1}, \\
V_{d I 2}=a_{I 2} V_{k} \cos \phi_{I 2}, \\
I_{d I 1}=\frac{V_{d R}-V_{d I 1}}{R_{d}}, \\
I_{d I 2}=\frac{V_{d R}-V_{d I 2}}{R_{d}}, \\
I_{d R}=I_{d I 1}+I_{d I 2}, \\
P_{d R}=V_{d R} I_{d R}, \\
P_{d I 2}=V_{d I 2} *\left[\frac{V_{d R}-V_{d I 2}}{R_{d}}\right] . \\
P_{d I 1} *\left[\frac{V_{d R}-V_{d I 1}}{R_{d}}\right]
\end{gathered}
$$

From the above, it can be observed that twelve independent equations exist as against a total of eighteen unknowns. Thus, for a complete solution of the HVDC quantities, six quantities (two per converter) are needed to be specified. These are derived from the control specifications adopted for the DC links. Each combination of a set of valid control specifications is known as a control strategy. Theoretically, the number of possible control strategies increases drastically with increase in the number of the DC terminals or converters. However, only a few of the possible control strategies are practically adopted in practice. This is explained in the next section.

\section{MTDC Control Strategies}

As already discussed in the previous section, for a threeterminal DC network, a myriad of control strategies are possible. However, due to a lack of space, only nine typical control strategies are considered in this paper. These are detailed in Table 1.

3.1. Control Strategy 1. In this control strategy, the DC voltage and the firing angle are specified for the rectifier. On the other hand, the active powers for both inverters are specified along with their extinction angles.

3.2. Control Strategy 2. In this control strategy, the DC voltage and the firing angle are specified for the rectifier. For inverter 1 , the active power is specified while the DC current is specified for inverter 2 . In addition, the extinction angles of both inverters are specified.

3.3. Control Strategy 3. In this control strategy, at the rectifier terminal, the DC voltage and the firing angle are specified. The DC current is specified at inverter 1 while the active power is specified at inverter 2 . Also, the extinction angles of both inverters are specified.

3.4. Control Strategy 4. In this control strategy, the DC voltage and the firing angle are specified at the rectifier end while the DC currents and the extinction angles are specified for both inverters.

3.5. Control Strategy 5. In this control strategy, the DC voltage is specified for the rectifier while the active powers are specified for both inverters. In addition, the tap settings for all the three converter transformers are specified.

3.6. Control Strategy 6. In this control strategy, the DC voltage is specified for the rectifier while the DC currents are 
specified for both inverters. The tap settings for all the three converter transformers are also specified.

3.7. Control Strategy 7. In this control strategy, at the rectifier terminal, the DC voltage is specified. The active power is specified at inverter 1 while the DC current is specified at inverter 2. In addition, the tap settings are specified for all the three converter transformers.

3.8. Control Strategy 8. In this control strategy, the DC voltage is specified at the rectifier terminal. For inverter 1 , the DC current is specified while for inverter 2 the active power is specified. The tap settings for all the three converter transformers are also specified.

3.9. Control Strategy 9. In this control strategy, the firing angle is specified for the rectifier while the DC voltage is specified for inverter 1 . In addition, the values of the active powers and the extinction angles are specified for both inverters.

\section{AC-DC Power-Flow Equations}

As already discussed in Section 1, for solving the AC-MTDC system, two additional equations per converter are required, which are derived from the control specifications adopted for the system. For the three-terminal DC link considered in this paper, this translates into six specified variables. These six specified variables are divided into two subsets. The first set of specified variables is used only for the DC load flow and corresponds to specifying active power or current at all terminals except at the voltage setting terminal. In this paper, the DC load flow is solved by the Newton-Raphson method.

Subsequently, for solving the AC power flow, the effects of the DC links are included in the power-flow equations by injecting an equivalent amount of real and reactive power at the terminal $\mathrm{AC}$ buses connected to the converters. The values of these active and reactive powers are computed using the specified variables and the variables computed from the DC power flow. This results in appropriate modifications of the mismatch equations at the converter terminal AC buses. These are given below.

For any AC bus " $i$," which is not connected to any DC link, the mismatches in the active and reactive power injections are given, respectively, by

$$
\begin{aligned}
& \Delta P_{i}=P_{i}^{\mathrm{sp}}-\sum_{k=1}^{n} V_{i} V_{k} Y_{i k} \cos \left(\theta_{i}-\theta_{k}-\phi_{i k}\right), \\
& \Delta Q_{i}=Q_{i}^{\mathrm{sp}}-\sum_{k=1}^{n} V_{i} V_{k} Y_{i k} \sin \left(\theta_{i}-\theta_{k}-\phi_{i k}\right) .
\end{aligned}
$$

The DC network contains two HVDC links. The first link is connected in the branches " $i$ " and " $j$ " between any two buses " $i$ " and " $j$ " of the network while the second one is connected in the branch " $i-k$ " between system buses " $i$ " and " $k$." The three converters representing one rectifier and two inverters are connected to the AC system at buses " $i$," “ $j$," and " $k$," respectively, through their respective converter transformers. The effect of the DC link can be incorporated in the AC power flow as equivalent active and reactive power injections " $P_{d R}$ " and " $Q_{d R}$ " at the rectifier bus " $i$," along with " $P_{d I 1}$ " and " $Q_{d I 1}$ " and " $P_{d I 2}$ " and " $Q_{d I 2}$ " at the inverter buses " $j$ " and " $k$," respectively. Therefore, the mismatches in the active and reactive power injections can be written as

$$
\begin{gathered}
\Delta P_{i}=P_{i}^{\mathrm{sp}}-\sum_{p=1}^{n} V_{i} V_{p} Y_{i p} \cos \left(\theta_{i}-\theta_{p}-\phi_{i p}\right)-P_{d R}, \\
\Delta Q_{i}=Q_{i}^{\mathrm{sp}}-\sum_{p=1}^{n} V_{i} V_{p} Y_{i p} \sin \left(\theta_{i}-\theta_{p}-\phi_{i p}\right)-Q_{d R}, \\
\Delta P_{j}=P_{j}^{\mathrm{sp}}-\sum_{p=1}^{n} V_{j} V_{p} Y_{j p} \cos \left(\theta_{j}-\theta_{p}-\phi_{j p}\right)+P_{d I 1}, \\
\Delta Q_{j}=Q_{j}^{\mathrm{sp}}-\sum_{p=1}^{n} V_{j} V_{p} Y_{j p} \sin \left(\theta_{j}-\theta_{p}-\phi_{j p}\right)-Q_{d I 1}, \\
\Delta P_{k}=P_{k}^{\mathrm{sp}}-\sum_{p=1}^{n} V_{k} V_{p} Y_{k p} \cos \left(\theta_{k}-\theta_{p}-\phi_{k p}\right)+P_{d I 2}, \\
\Delta Q_{k}=Q_{k}^{\mathrm{sp}}-\sum_{p=1}^{n} V_{k} V_{p} Y_{k p} \sin \left(\theta_{k}-\theta_{p}-\phi_{k p}\right)-Q_{d I 2},
\end{gathered}
$$

where $P_{d R}=V_{d R} I_{d R}, Q_{d R}=P_{d R} \tan \phi_{R}, P_{d I 1}=V_{d I 1} I_{d I 1}$, $Q_{d I 1}=P_{d I 1} \tan \phi_{I 1}, P_{d I 2}=V_{d I 2} I_{d I 2}$, and $Q_{d I 2}=P_{d I 2} \tan \phi_{I 2}$. In the above equations, the equivalent active power injections " $P_{d R}$ " " $P_{d I 1}$ " and " $P_{d I 2}$ " are usually specified or can be very easily computed by manipulation of the specified variables. However, for the equivalent reactive power injections $Q_{d R}$, $Q_{d I 1}$, and $Q_{d I 2}$, the case is different, depending on the control strategy adopted for the DC links. For control strategies 1, 2, 3,4 , and $9, \phi_{R}, \phi_{I 1}$, and $\phi_{I 2}$ (and hence $Q_{d R}, Q_{d I 1}$, and $Q_{d I 2}$ ) can be computed by manipulation of the specified variables. However, for control strategies $5,6,7$, and $8, \phi_{R}, \phi_{I 1}$, and $\phi_{I 2}$ (and hence $Q_{d R}, Q_{d I 1}$, and $Q_{d I 2}$ ) are dependent on both the specified variables and the AC state variables, which are updated in every iteration. This affects the convergence pattern. The steps involved in the computation of the active and reactive power injections for only two typical control strategies 1 and 5 are detailed in Table 7 . In control strategy 5 the reactive power injections are dependent on the AC power-flow iterative process while in control strategy 1 they are independent of it. Although the steps involved in the computation of the power injections pertaining to the rest of the control strategies are not shown due to limitations of space, they can be computed in ways similar to control strategies 1 and 5 .

It is important to note the conventions of the signs of the equivalent real and reactive power injections representing the DC link. It is assumed that the rectifier consumes both real and reactive power from the AC grid while the inverters supply real power and consume reactive power. 


\section{Case Studies and Results}

Numerous case studies were carried out on a three-terminal DC network comprising one rectifier and two inverters incorporated in the IEEE 300-bus test system [20]. All the three converters are connected to their respective AC buses by tap changing transformers. Although a large number of control strategies are possible with the three-terminal DC network, however, due to limitations of space, only results corresponding to nine different control strategies are reported here. For all the case studies, the commutating reactance and the DC link resistance were chosen as 0.1 p.u. and 0.01 p.u., respectively. The number of bridges " $n_{b}$ " for all the converters was taken to be equal to 2 . To minimize the reactive power requirement at the rectifier and inverter terminals and the overall system losses, the rectifier firing angles and the inverter extinction angles are kept within $5^{\circ}$ to $15^{\circ}$ and $15^{\circ}$ to $22^{\circ}$, respectively, for all the case studies. In a similar manner, the tap ratios of the converter transformers are kept between 0.85 and 1.15. A convergence tolerance of $10^{-12}$ p.u. was uniformly adopted for all the case studies. In each of the case studies, "NI" refers to the number of iterations taken by the algorithm to converge to the specified tolerance $\left(10^{-12}\right.$ p.u. $)$. In general, "NI" is representative of the degree of convergence of a power-flow study.

Case Study I. In this case study, two HVDC links are considered. The first link is incorporated between buses " $25-26$ " and the second one between buses "25-232." The converter connected to bus number 25 acts as a rectifier. On the other hand, both converters connected to buses 26 and 232 act as inverters. Control strategy 1 is adopted for the control of the DC links. Corresponding to this strategy, the active power flows on the links $25-26$ and 25-232 are set to 0.3 p.u. and 0.1 p.u., respectively. The DC voltage on the rectifier side is set at $1 \mathrm{p} . \mathrm{u}$. The firing angle for the rectifier and the extinction angles for both inverters are set to $5^{\circ}$ and $15^{\circ}$, respectively. The power-flow solution is shown in columns 5-8 of Table 2 (corresponding to control strategy 1). The state variables pertaining to the AC and DC systems are denoted as ACSV and DCSV, respectively. From Table 2, it is observed that the power-flow convergence pattern in this case is similar to that of the base case power flow (without HVDC link), converging in seven iterations. This is because the power injections representing the DC links can be computed prior to the $\mathrm{AC}$ power flow, as elaborated from the steps given in the first column of Table 7. This is reiterated from the convergence characteristics corresponding to the base case and case study 1, as shown in Figures 2 and 3, respectively. The convergence characteristic plots the error (maximum absolute mismatch in p.u.) against the number of iterations "NI."

Case Study II. In this case study, two HVDC links are connected between buses "213-214" and "213-216." While the converter connected to bus number 213 acts as a rectifier, both converters connected to buses 214 and 216 act as inverters. In this case, control strategy 2 is adopted for the control of the DC links. The rectifier end DC voltage is specified along with the firing angle. While the first inverter acts on constant power mode, the second one acts on the constant current mode. In addition, the extinction angles for both inverters are specified. These values are detailed in columns $1-4$ of Table 2 (corresponding to control strategy 2). The power-flow solution is detailed in columns $5-8$ of Table 2 . The convergence pattern is similar to that of control strategy 1 , as the DC link power injections can be computed prior to the AC power flow. The steps involved in the computation of the DC link power injections (Table 7), although similar in nature to control strategy 1 , are not shown due to limitations of space.

Case Study III. In this case, two HVDC links are connected between buses "109-146" and "109-147." The converter connected to bus number 109 acts as a rectifier, while both converters connected to buses 146 and 147 act as inverters. For control of the DC links, control strategy 3 is selected. The rectifier end DC voltage is specified along with the firing angle. While the first inverter acts on constant current mode, the second one acts on the constant power mode. In addition, the extinction angles for both inverters are specified. These values are detailed in columns 1-4 of Table 2 . The power-flow solution is detailed in columns $5-8$ of Table 2 (corresponding to control strategy 3). From Table 2, it is observed that the convergence pattern obtained in this case is again similar to control strategies 1 and 2, which is expected as the power injections can be computed prior to the AC power flow.

Case Study IV. In this case study, two HVDC links are connected between buses "101-102" and "101-104." The rectifier is connected to bus number 101 . The inverters are connected to buses 102 and 104, respectively. For control of the two DC links, control strategy 4 is adopted. The rectifier end DC voltage is specified along with the firing angle. Both inverters are operated at constant current and constant extinction angle modes. The values of the specified quantities are detailed in columns 1-4 of Table 3. The power-flow solution is detailed in columns 5-8 of Table 3 (corresponding to control strategy 4). It is observed that as expected the convergence pattern is similar to that obtained with control strategies 1 to 4 (since the DC link power injections are known before the AC power flow).

Case Study V. In this case, two HVDC links are incorporated between buses " $86-87$ " and " $86-90$." The converter connected to bus number 86 acts as a rectifier while both converters connected to buses 87 and 90 act as inverters. Control strategy 5 is selected for the control of the DC links. In this strategy, the rectifier end DC voltage is specified while both inverters are operated in the constant power mode. In addition, the tap ratios of all the three converter transformers are specified. Columns 1-4 of Table 3 show these specified values. The power-flow solution is shown in columns 58 of Table 3 (corresponding to control strategy 5). From the power-flow solution, it is observed that, unlike control strategies 1 to 4 , with this control strategy, the convergence pattern is adversely affected. This is because for this control strategy the computation of the reactive power injections (for the DC links) is dependent on the AC power-flow variables 
TABLE 2: Study of IEEE-300 bus system with a three-terminal DC network.

\begin{tabular}{|c|c|c|c|c|c|c|c|}
\hline \multirow{2}{*}{$\begin{array}{r}\mathrm{HI} \\
\text { Rectifier bus }\end{array}$} & \multirow{2}{*}{$\begin{array}{l}\text { links } \\
\text { Inverter buses }\end{array}$} & \multirow{2}{*}{\multicolumn{2}{|c|}{$\begin{array}{l}\text { HVDC link specification } \\
\text { Control strategy } 1 \\
\text { Spec. values }\end{array}$}} & \multicolumn{4}{|c|}{ Power-flow solution } \\
\hline & & & & \multicolumn{2}{|c|}{$\begin{array}{c}\text { AC terminal buses } \\
\text { ACSV }\end{array}$} & \multicolumn{2}{|c|}{$\begin{array}{c}\text { HVDC variables } \\
\text { DCSV }\end{array}$} \\
\hline \multirow{13}{*}{25} & \multirow{9}{*}{26} & \multirow{3}{*}{$\begin{array}{l}P_{d I 1} \\
\text { (p.u.) }\end{array}$} & & & \multirow{3}{*}{0.9632} & $V_{d I 1}$ & 0.998 \\
\hline & & & \multirow[t]{2}{*}{0.2} & $V_{25}$ & & $V_{d I 2}$ & 0.999 \\
\hline & & & & & & $P_{d R}$ & 0.3005 \\
\hline & & \multirow{3}{*}{$\begin{array}{l}P_{d I 2} \\
\text { (p.u.) }\end{array}$} & \multirow{3}{*}{0.1} & & \multirow{3}{*}{$-2.122^{\circ}$} & $I_{d I 1}$ & 0.2004 \\
\hline & & & & $\theta_{25}$ & & $I_{d I 2}$ & 0.1001 \\
\hline & & & & & & $I_{d R}$ & 0.3005 \\
\hline & & \multirow{3}{*}{$\begin{array}{l}V_{d R} \\
\text { (p.u.) }\end{array}$} & \multirow{3}{*}{1} & & \multirow{3}{*}{0.9564} & $a_{R}$ & 1.0386 \\
\hline & & & & $V_{26}$ & & $a_{I 1}$ & 1.103 \\
\hline & & & & & & $a_{I 2}$ & 1.0441 \\
\hline & \multirow{4}{*}{232} & \multirow{2}{*}{$\begin{array}{l}\alpha_{R} \\
\text { (deg.) }\end{array}$} & \multirow{2}{*}{5} & $\theta_{26}$ & \multirow{2}{*}{$-3.715^{\circ}$} & $\cos \phi_{R}$ & 0.9766 \\
\hline & & & & $v_{26}$ & & $\cos \phi_{I 1}$ & 0.9377 \\
\hline & & $\begin{array}{l}\gamma_{I 1} \\
\text { (deg.) }\end{array}$ & 15 & $V_{232}$ & 0.9841 & $\cos \phi_{I 2}$ & 0.9563 \\
\hline & & $\begin{array}{l}\gamma_{I 2} \\
\text { (deg.) }\end{array}$ & 15 & $\theta_{232}$ & $-1.792^{\circ}$ & NI & 7 \\
\hline & & & & & al buses & $\mathrm{HV}$ & ables \\
\hline & & & & & & & \\
\hline & & & & & & $V_{d I 1}$ & 0.994 \\
\hline & & $\begin{array}{l}P_{d I 1} \\
\text { (p.u.) }\end{array}$ & 0.6 & $V_{213}$ & 1.0067 & $V_{d I 2}$ & 0.996 \\
\hline & 214 & & & & & $P_{d I 2}$ & 0.4036 \\
\hline & 21 & & & & & $P_{d R}$ & 1.0036 \\
\hline & & $\begin{array}{l}I_{d I 2} \\
\text { (p.u.) }\end{array}$ & 0.4 & $\theta_{213}$ & $-21.69^{\circ}$ & $I_{d I 1}$ & 0.6036 \\
\hline & & & & & & $I_{d R}$ & 1.0036 \\
\hline 213 & & & & & & $a_{R}$ & 1.0972 \\
\hline & & $\begin{array}{l}V_{d R} \\
(\mathrm{p}, \mathrm{u})\end{array}$ & 1 & $V_{214}$ & 1.0087 & $a_{I 1}$ & 1.0822 \\
\hline & & & & & & $a_{I 2}$ & 1.0187 \\
\hline & & $\alpha_{R}$ & 5 & $\theta_{214}$ & $-21.125^{\circ}$ & $\cos \phi_{R}$ & 0.9053 \\
\hline & & (deg.) & J & 214 & 21.120 & $\cos \phi_{I 1}$ & 0.9106 \\
\hline & 216 & $\begin{array}{l}\gamma_{I 1} \\
\text { (deg.) }\end{array}$ & 15 & $V_{216}$ & 1.0528 & $\cos \phi_{I 2}$ & 0.9286 \\
\hline & & $\begin{array}{l}\gamma_{I 2} \\
\text { (deg.) }\end{array}$ & 15 & $\theta_{216}$ & $-21.39^{\circ}$ & NI & 7 \\
\hline & & & & & al buses & $\mathrm{HV}$ & ables \\
\hline & & & & & & & \\
\hline & & & & & & $V_{d I 1}$ & 0.999 \\
\hline & & (p.u.) & 0.1 & $V_{109}$ & 0.9993 & $V_{d I 2}$ & 0.996 \\
\hline & 146 & & & & & $P_{d R}$ & 0.1101 \\
\hline & & & & & & $P_{d I 1}$ & 0.0101 \\
\hline & & (p.u.) & 0.01 & $\theta_{109}$ & $5.6163^{\circ}$ & $I_{d I 2}$ & 0.1001 \\
\hline & & & & & & $I_{d I R}$ & 0.1101 \\
\hline 109 & & & & & & $a_{R}$ & 1.1151 \\
\hline & & $\begin{array}{l}V_{d R} \\
\text { (p.u.) }\end{array}$ & 1 & $V_{146}$ & 0.9618 & $a_{I 1}$ & 1.0871 \\
\hline & & & & & & $a_{I 2}$ & 1.1439 \\
\hline & & $\alpha_{R}$ & 5 & $\theta_{146}$ & $-7.1728^{\circ}$ & $\cos \phi_{R}$ & 0.8974 \\
\hline & 147 & (deg.) & & & & $\cos \phi_{I 1}$ & 0.9564 \\
\hline & $14 /$ & $\begin{array}{l}\gamma_{I 1} \\
\text { (deg.) }\end{array}$ & 15 & $V_{147}$ & $0.9947^{\circ}$ & $\cos \phi_{I 2}$ & 0.878 \\
\hline & & $\begin{array}{l}\gamma_{I 2} \\
\text { (deg.) }\end{array}$ & 15 & $\theta_{147}$ & $-4.9558^{\circ}$ & NI & 7 \\
\hline
\end{tabular}


TABLE 3: Study of IEEE-300 bus system with a three-terminal HVDC network.

\begin{tabular}{|c|c|c|c|c|c|c|c|}
\hline \multicolumn{2}{|c|}{ HVDC link } & \multirow{2}{*}{\multicolumn{2}{|c|}{$\begin{array}{c}\text { HVDC link specification } \\
\text { Control strategy } 4 \\
\text { Spec. values }\end{array}$}} & \multicolumn{4}{|c|}{ Power-flow solution } \\
\hline Rectifier bus & Inverter buses & & & \multicolumn{2}{|c|}{$\begin{array}{c}\text { AC terminal buses } \\
\text { ACSV }\end{array}$} & \multicolumn{2}{|c|}{$\begin{array}{c}\text { HVDC variables } \\
\text { DCSV }\end{array}$} \\
\hline \multirow{13}{*}{101} & \multirow{6}{*}{102} & \multirow{3}{*}{$\begin{array}{l}I_{d I 1} \\
\text { (p.u.) }\end{array}$} & \multirow{3}{*}{0.5} & \multirow{3}{*}{$V_{101}$} & \multirow{3}{*}{0.9621} & $V_{d I 1}$ & 0.995 \\
\hline & & & & & & $V_{d I 2}$ & 0.996 \\
\hline & & & & & & $P_{d I 1}$ & 0.3984 \\
\hline & & \multirow{3}{*}{$\begin{array}{l}I_{d I 2} \\
\text { (p.u.) }\end{array}$} & \multirow{3}{*}{0.4} & \multirow{3}{*}{$\theta_{101}$} & \multirow{3}{*}{$-16.34^{\circ}$} & $P_{d I 2}$ & 0.4975 \\
\hline & & & & & & $P_{d R}$ & 0.9 \\
\hline & & & & & & $I_{d R}$ & 0.9 \\
\hline & & \multirow{3}{*}{$\begin{array}{l}V_{d R} \\
\text { (p.u.) }\end{array}$} & \multirow{3}{*}{1} & \multirow{3}{*}{$V_{102}$} & \multirow{3}{*}{0.997} & $a_{R}$ & 1.137 \\
\hline & & & & & & $a_{I 1}$ & 1.0851 \\
\hline & & & & & & $a_{I 2}$ & 1.0616 \\
\hline & & \multirow{2}{*}{$\begin{array}{l}\alpha_{R} \\
\text { (deg.) }\end{array}$} & \multirow[t]{2}{*}{5} & $\theta_{1}$ & -16.658 & $\cos \phi_{R}$ & 0.9139 \\
\hline & & & & 102 & -10.000 & $\cos \phi_{I 1}$ & 0.9197 \\
\hline & 104 & $\begin{array}{l}\gamma_{I 1} \\
\text { (deg.) }\end{array}$ & 15 & $V_{104}$ & 1.0103 & $\cos \phi_{I 2}$ & 0.9286 \\
\hline & & $\begin{array}{l}\gamma_{I 2} \\
\text { (deg.) }\end{array}$ & 15 & $\theta_{104}$ & $-18.43^{\circ}$ & NI & 7 \\
\hline & & & & & al buses & $\mathrm{HV}$ & iables \\
\hline & & & & & & & \\
\hline & & & & & & $V_{d I 1}$ & 0.997 \\
\hline & & $\begin{array}{l}P_{d I 1} \\
(\mathrm{n} \mathrm{u})\end{array}$ & 0.3 & $V_{86}$ & 1.007 & $V_{d I 2}$ & 0.998 \\
\hline & & & & & & $P_{d R}$ & 0.5 \\
\hline & & & & & & $I_{d I 1}$ & 0.3009 \\
\hline & 87 & $\begin{array}{l}P_{d I 2} \\
(\mathrm{pu})\end{array}$ & 0.2 & $\theta_{86}$ & -13.843 & $I_{d I 2}$ & 0.2004 \\
\hline & & & & & & $I_{d R}$ & 0.5021 \\
\hline 86 & & & & & & $\alpha_{R}$ & 15.266 \\
\hline & & $\begin{array}{l}V_{d R} \\
(\mathrm{p}, \mathrm{u})\end{array}$ & 1 & $V_{87}$ & 0.996 & $\gamma_{I 1}$ & 20.363 \\
\hline & & & & & & $\gamma_{I 2}$ & 17.314 \\
\hline & & $a_{\mathrm{p}}$ & 1.08 & $\theta_{87}$ & -23.842 & $\cos \phi_{R}$ & 0.9187 \\
\hline & & $u_{R}$ & 1.00 & $0_{87}$ & -25.042 & $\cos \phi_{I 1}$ & 0.91 \\
\hline & 90 & $a_{I 1}$ & 1.1 & $V_{90}$ & 0.9694 & $\cos \phi_{I 2}$ & 0.9359 \\
\hline & & $a_{I 2}$ & 1.1 & $\theta_{90}$ & -23.842 & NI & 12 \\
\hline & & & & & al buses & $\mathrm{HV}$ & iables \\
\hline & & & & & & & \\
\hline & & & & & & $V_{d I 1}$ & 0.998 \\
\hline & & $I_{d I 1}$ & 0.2 & $V_{77}$ & 1.052 & $V_{d I 2}$ & 0.999 \\
\hline & 84 & & & & & $P_{d I 1}$ & 0.1996 \\
\hline & & & & & & $P_{d I 2}$ & 0.0999 \\
\hline & & $\begin{array}{l}I_{d I 2} \\
\text { (p.u.) }\end{array}$ & 0.1 & $\theta_{77}$ & $-6.815^{\circ}$ & $P_{d R}$ & 0.3 \\
\hline & & & & & & $I_{d R}$ & 0.3 \\
\hline 77 & & & & & & $\alpha_{R}$ & 14.212 \\
\hline & & $\begin{array}{l}v d R \\
\text { (p.u.) }\end{array}$ & 1 & $V_{84}$ & 1.0272 & $\gamma_{I 1}$ & 17.647 \\
\hline & & & & & & $\gamma_{I 2}$ & 17.985 \\
\hline & & $a_{p}$ & 1.01 & $\theta_{84}$ & -11.694 & $\cos \phi_{R}$ & 0.9412 \\
\hline & 86 & $a_{R}$ & 1.01 & $\sigma_{84}$ & -11.094 & $\cos \phi_{I 1}$ & 0.9342 \\
\hline & & $a_{I 1}$ & 1.04 & $V_{86}$ & 1.02 & $\cos \phi_{I 2}$ & 0.9417 \\
\hline & & $a_{I 2}$ & 1.09 & $\theta_{86}$ & $-12.81^{\circ}$ & $\mathrm{NI}$ & 10 \\
\hline
\end{tabular}

and is updated in every iteration. This is elaborated from the steps involved in the computation of the power injections as shown in the second column of Table 7. From Table 7, it can be observed that the computation of the reactive power injections is dependent on the iterative process. This affects the convergence pattern. This is reiterated by comparing the convergence characteristics for this case, as shown in Figure 4, with those of Figures 2 and 3.

The bus voltage profile for this control strategy is shown in Figure 5. It is observed that the bus voltage profiles undergo very slight changes at only the AC terminal buses connected to the converters. 


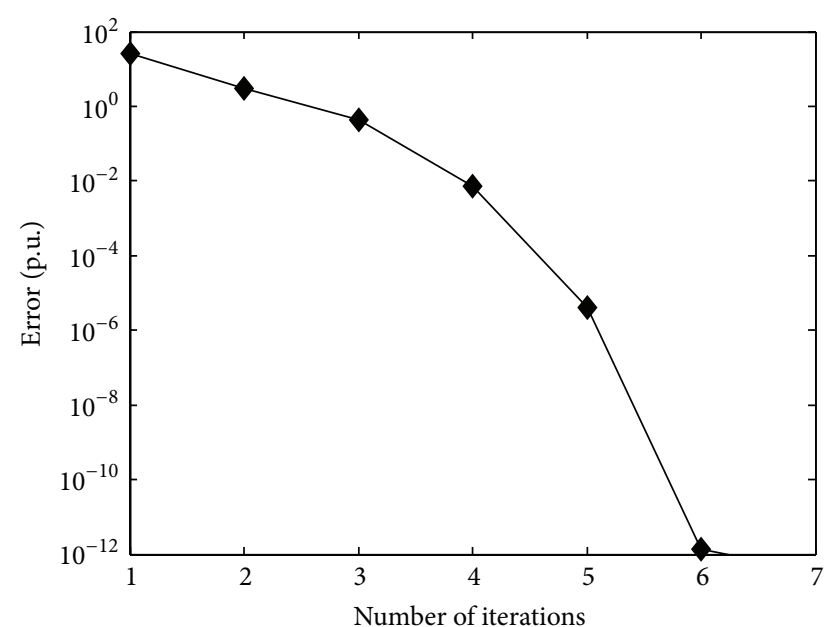

FIgURE 2: Convergence characteristics for the base case power flow in IEEE-300 bus test system.

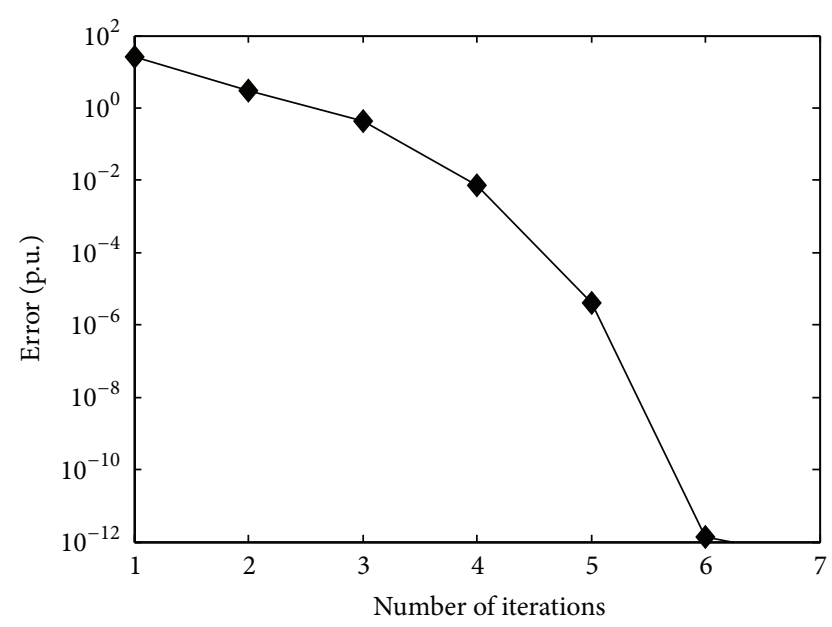

Figure 3: Convergence characteristics for case study I of Table 2 with control strategy 1 .

It is important to note that due to a limitation of space only the bus voltage profile corresponding to control strategy 5 is shown. This is because among all the case studies carried out the poorest power-flow convergence pattern was observed corresponding to this control strategy.

Case Study VI. In this case, the two HVDC links were incorporated between buses "77-84" and "77-86." While the converter connected to bus number 77 acts as a rectifier, both converters connected to buses 84 and 86 act as inverters. For control of the DC links, control strategy 6 is adopted. In this control strategy, the rectifier end DC voltage is specified. On the other hand, both inverters are operated in the constant current mode. Also, the tap ratios of all the three converter transformers are specified. While columns " $1-4$ " of Table 3 show the values of the specified quantities, columns 5-8 detail the power-flow solution (corresponding to control strategy 6). From the power-flow solution it is observed that

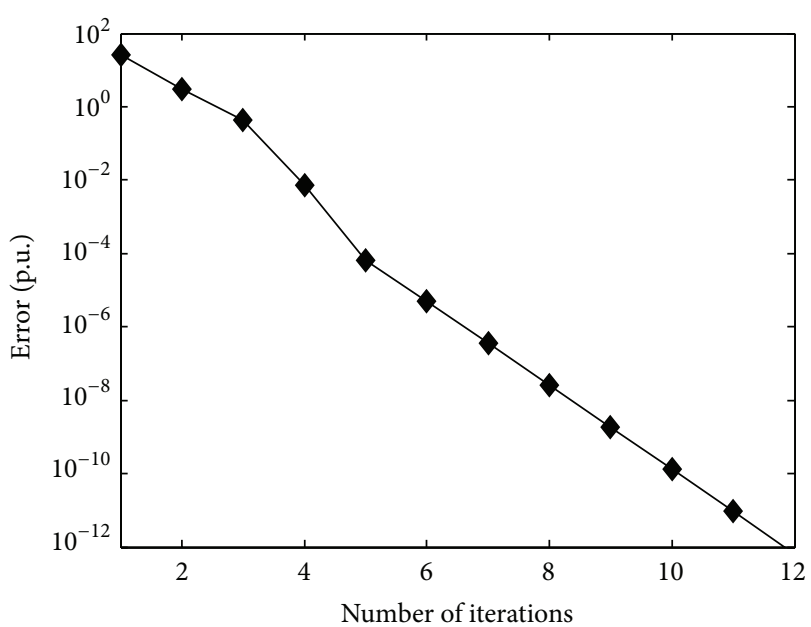

FIgURE 4: Convergence characteristics for case study V of Table 3 with control strategy 5 .

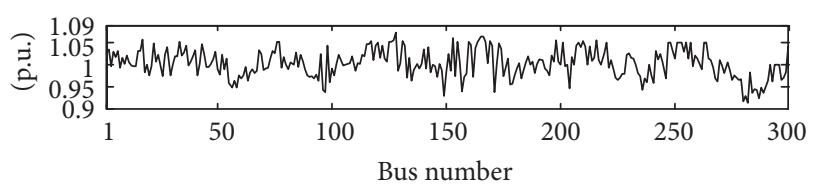

(a) Bus voltage magnitude without HVDC link

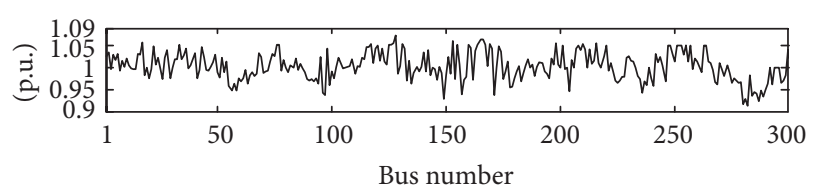

(b) Bus voltage magnitude with HVDC link

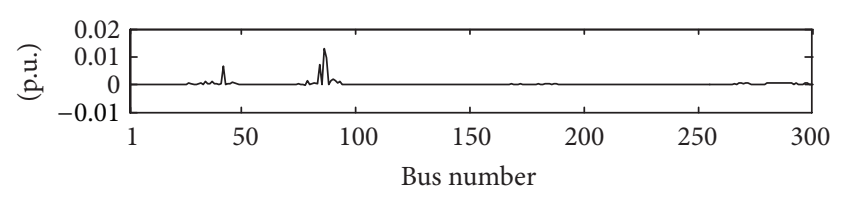

(c) Bus voltage magnitude difference

FIGURE 5: Bus voltage profile for case study $\mathrm{V}$ with control strategy 5 .

in this case the convergence pattern is adversely affected as in case of that of control strategy 5 . This is because the converter equivalent reactive power injections are required to be updated in every iteration of the AC power flow. This is also true for the subsequent case studies VII and VIII carried out employing control strategies 7 and 8, respectively. Although the steps involved in the computation of the power injections with control strategies 6 to 8 are similar to those with control strategy 5 (second column, Table 7), they are not shown due to limitations of space.

The convergence characteristics corresponding to this case study are shown in Figure 6. By comparing Figures 5 and 6 , the similarity in the convergence characteristics between the case studies with control strategies 4 and 6 can be observed. 


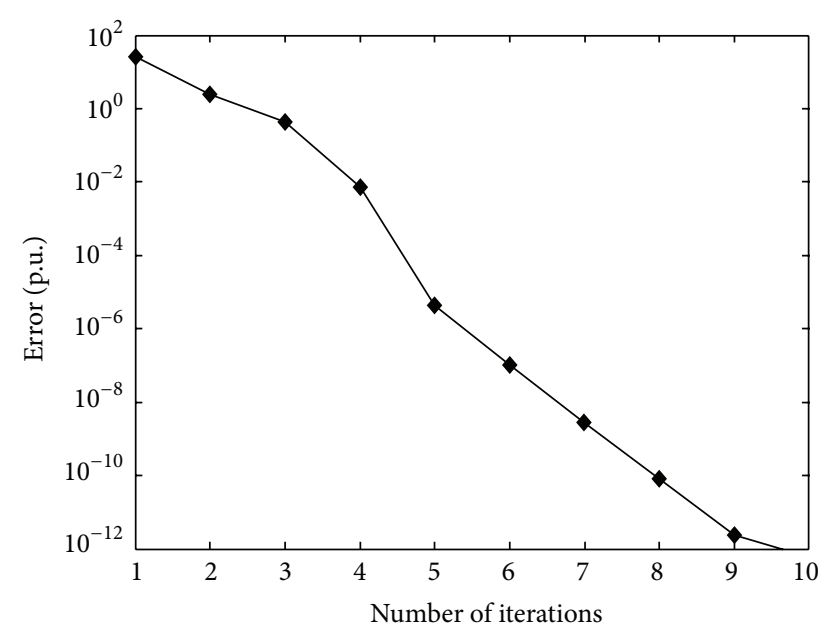

FIGURE 6: Convergence characteristics for case study VI of Table 3 with control strategy 6 .

Case Study VII. In this case study, two HVDC links are incorporated between buses "68-173" and "68-174." The converter connected to bus number 68 acts as a rectifier while both converters connected to buses 173 and 174 act as inverters. Control strategy 7 is selected for the control of the DC links. The first inverter is operated in the constant power mode while the second one operates in the constant current mode. In addition, the tap ratios of all the three converter transformers are specified. The specified values are given in columns 1-4 of Table 4 . The power-flow solution is shown in columns 5-8 of Table 4 (corresponding to control strategy 7). From the power-flow solution, it is observed that, similar to control strategies 5 and 6 , the convergence pattern for this control strategy is adversely affected. This is expected as the reactive power injections are dependent on the iterative process of the AC power flow. This is reiterated from the convergence characteristics for this case study, as shown in Figure 7.

Case Study VIII. In this case, two HVDC links are incorporated between buses "15-31" and "15-74." The converter connected to bus number 15 acts as a rectifier while both converters connected to buses 31 and 74 act as inverters. Control strategy 8 is selected for the control of the DC links. The rectifier operates in the constant voltage mode. The first and the second inverters are operated in the constant current and constant power modes, respectively. In addition, the tap ratios of all the three converter transformers are specified. Columns 1-4 of Table 4 show these specified values. The power-flow solution is shown in columns 5-8 of Table 4 (corresponding to control strategy 8 ). From the power-flow solution, it is again observed that, similar to control strategies $5-7$, the convergence pattern is adversely affected by this control strategy. The convergence characteristics for this case study, as shown in Figure 8, emphasise this fact.

Case Study IX. In this case, two HVDC links are incorporated between buses "266-270" and "266-271." The converter

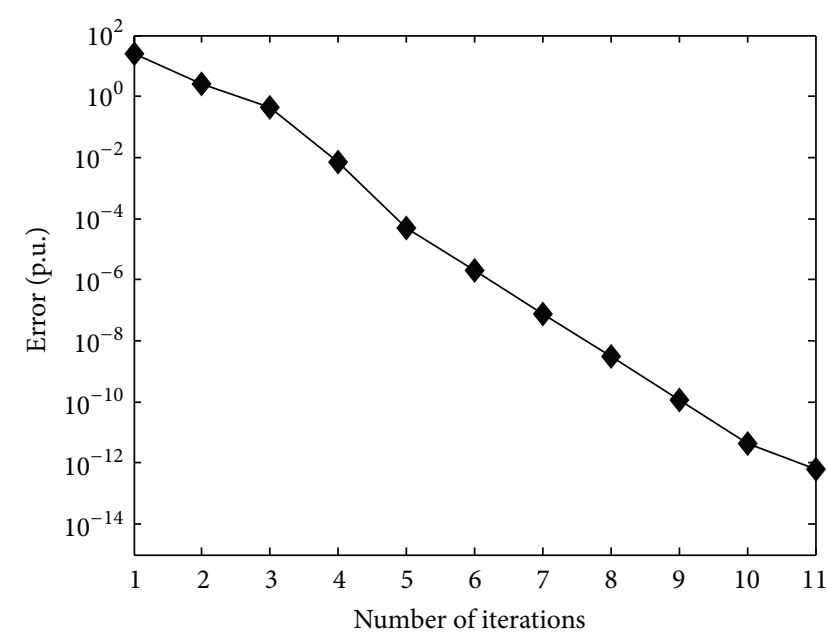

FIgURE 7: Convergence characteristics for case study VII of Table 4 with control strategy 7 .

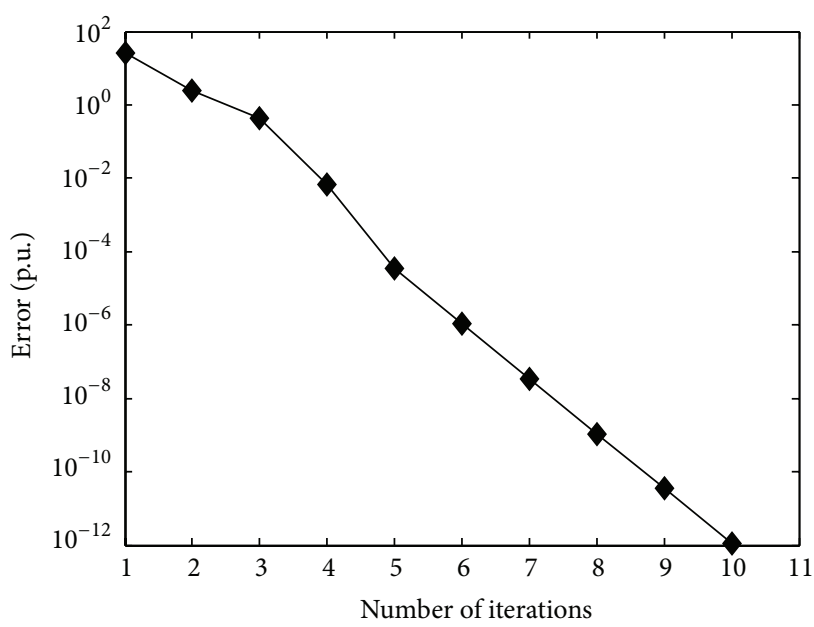

FIGURE 8: Convergence characteristics for case study VIII of Table 4 with control strategy 8 .

connected to bus number 266 acts as a rectifier while both converters connected to buses 270 and 271 act as inverters. Control strategy 9 is selected for the control of the DC links. In this strategy, the rectifier is operated in the constant firing angle mode. Both inverters are operated in constant power and constant extinction angle mode. Columns 1-4 of Table 4 show these specified values. The power-flow solution is shown in columns 5-8 of Table 4 (corresponding to control strategy 9). From Table 4, it is observed that, in this case study, the convergence pattern is better than those with control strategies $5-8$. This is because the power injections representing the DC link can be computed a priori and are independent of the iterative process of the AC power flow. This is reiterated by the convergence characteristics for this case study, as shown in Figure 9.

The convergence patterns for the control strategies 2, 3, 4, and 9 , although similar to control strategy 1 , are not shown due to the limitations of space. 
TABLE 4: Study of IEEE-300 bus system with three-terminal HVDC network.

\begin{tabular}{|c|c|c|c|c|c|c|c|}
\hline \multicolumn{2}{|c|}{ HVDC link } & \multirow{3}{*}{\multicolumn{2}{|c|}{$\begin{array}{c}\text { HVDC link specification } \\
\text { Control strategy } 7 \\
\text { Spec. values }\end{array}$}} & \multicolumn{4}{|c|}{ Power-flow solution } \\
\hline \multirow[t]{2}{*}{ Rectifier bus } & \multirow[t]{2}{*}{ Inverter buses } & & & \multirow{2}{*}{\multicolumn{2}{|c|}{$\begin{array}{c}\text { AC terminal buses } \\
\text { ACSV }\end{array}$}} & \multirow{2}{*}{\multicolumn{2}{|c|}{$\begin{array}{c}\text { HVDC variables } \\
\text { DCSV }\end{array}$}} \\
\hline & & & & & & & \\
\hline \multirow{13}{*}{68} & \multirow{9}{*}{173} & \multirow{3}{*}{$\begin{array}{l}P_{d I 1} \\
\text { (p.u.) }\end{array}$} & \multirow{3}{*}{0.5} & \multirow{3}{*}{$V_{68}$} & \multirow{3}{*}{1.019} & $V_{d I 1}$ & 0.995 \\
\hline & & & & & & $V_{d I 2}$ & 0.9995 \\
\hline & & & & & & $P_{d I 2}$ & 0.05 \\
\hline & & \multirow{3}{*}{$\begin{array}{l}I_{d I 2} \\
\text { (p.u.) }\end{array}$} & \multirow{3}{*}{0.1} & \multirow{3}{*}{$\theta_{68}$} & \multirow{3}{*}{-19.200} & $P_{d R}$ & 0.5525 \\
\hline & & & & & & $I_{d I 1}$ & 0.5025 \\
\hline & & & & & & $I_{d R}$ & 0.6025 \\
\hline & & \multirow{3}{*}{$\begin{array}{l}V_{d R} \\
\text { (p.u.) }\end{array}$} & \multirow{3}{*}{1} & \multirow{3}{*}{$V_{173}$} & \multirow{3}{*}{1.0363} & $\alpha_{R}$ & 12.373 \\
\hline & & & & & & $\gamma_{I 1}$ & 22.275 \\
\hline & & & & & & $\gamma_{I 2}$ & 21.965 \\
\hline & & \multirow{2}{*}{$a_{R}$} & 1.06 & $\theta_{173}$ & -18.849 & $\cos \phi_{R}$ & 0.9256 \\
\hline & & & & & & $\cos \phi_{I 1}$ & 0.8809 \\
\hline & 174 & $a_{I 1}$ & 1.09 & $V_{174}$ & 1.0315 & $\cos \phi_{I 2}$ & 0.9228 \\
\hline & & $a_{I 2}$ & 1.05 & $\theta_{174}$ & -20.83 & NI & 11 \\
\hline & & & & & hal buses & $\mathrm{HV}$ & ables \\
\hline & & & & & & & \\
\hline & & & & & & $V_{d I 1}$ & 0.9996 \\
\hline & & $\begin{array}{l}I_{d I 1} \\
\text { (p.u.) }\end{array}$ & 0.04 & $V_{15}$ & 1.0095 & $V_{d I 2}$ & 0.998 \\
\hline & 31 & & & & & $P_{d I 1}$ & 0.2299 \\
\hline & & & & & & $P_{d R}$ & 0.4299 \\
\hline & & $\begin{array}{l}I_{d I 2} \\
\text { (p.u.) }\end{array}$ & 0.2 & $\theta_{15}$ & -9.0928 & $I_{d I 2}$ & 0.2004 \\
\hline 15 & & & & & & $I_{d R}$ & 0.2404 \\
\hline & & & & & & $\alpha_{R}$ & 12.733 \\
\hline & & $\begin{array}{l}d R \\
\text { (p.u.) }\end{array}$ & 1 & $V_{31}$ & 1.0101 & $\gamma_{I 1}$ & 21.787 \\
\hline & & & & & & $\gamma_{I 2}$ & 22.78 \\
\hline & & $a_{R}$ & 1.04 & $\theta_{31}$ & -11.3 & $\cos \phi_{R}$ & 0.9525 \\
\hline & 7 & & & & & $\cos \phi_{I 1}$ & 0.9249 \\
\hline & 74 & $a_{I 1}$ & 1.07 & $V_{74}$ & 1.0224 & $\cos \phi_{I 2}$ & 0.9038 \\
\hline & & $a_{I 2}$ & 1.08 & $\theta_{74}$ & -10.272 & NI & 11 \\
\hline & & & & & tal buses & $\mathrm{HV}$ & ables \\
\hline & & & & & & & \\
\hline & & & & & & $V_{d R}$ & 0.996 \\
\hline & & $\begin{array}{l}P_{d I 1} \\
\text { (p.u.) }\end{array}$ & 0.4 & $V_{25}$ & 0.9965 & $V_{d I 2}$ & 0.997 \\
\hline & 270 & & & & & $P_{d R}$ & 0.7025 \\
\hline & & & & & & $I_{d I 1}$ & 0.4016 \\
\hline & & $\begin{array}{l}\text { (p.u. } \\
\text { (p.u.) }\end{array}$ & 0.3 & $\theta_{25}$ & -9.2266 & $I_{d I 2}$ & 0.3009 \\
\hline 266 & & & & & & $I_{d R}$ & 0.7025 \\
\hline & & $V_{d I 1}$ & 1 & & & $a_{R}$ & 1.0437 \\
\hline & & (p.u.) & 1 & $V_{26}$ & 0.9966 & $a_{I 1}$ & 1.1118 \\
\hline & & & & & & $a_{I 2}$ & 1.1358 \\
\hline & & $\alpha_{R}$ & 5 & $\theta_{26}$ & -9.1557 & $\cos \phi_{R}$ & 0.9576 \\
\hline & 271 & (deg.) & & & & $\cos \phi_{I 1}$ & 0.9025 \\
\hline & & $\begin{array}{l}\gamma_{I 1} \\
\text { (deg.) }\end{array}$ & 15 & $V_{232}$ & 0.9362 & $\cos \phi_{I 2}$ & 0.9376 \\
\hline & & $\begin{array}{l}\gamma_{I 2} \\
\text { (deg.) }\end{array}$ & 15 & $\theta_{232}$ & -7.6891 & NI & 6 \\
\hline
\end{tabular}


TABLE 5: Study of power-flow convergence pattern with active power in the second DC link.

\begin{tabular}{|c|c|c|c|c|c|}
\hline \multicolumn{2}{|c|}{ HVDC links } & \multirow{2}{*}{\multicolumn{2}{|c|}{$\begin{array}{l}\text { HVDC link specification } \\
\text { Control strategy } 5\end{array}$}} & \multirow{2}{*}{\multicolumn{2}{|c|}{$\begin{array}{l}\text { Power-flow solutions } \\
\text { HVDC variables }\end{array}$}} \\
\hline $\begin{array}{l}\text { Rectifier } \\
\text { bus }\end{array}$ & $\begin{array}{c}\text { Inverter } \\
\text { buses }\end{array}$ & & & & \\
\hline \multirow{6}{*}{85} & \multirow{6}{*}{88,233} & \multirow{6}{*}{$\begin{array}{l}P_{d I 1}=0.5 \\
\text { (p.u.) } \\
V_{d R}=1 \text { (p.u.) } \\
a_{R}=1.14 \\
a_{I 1}=1.1 \\
a_{I 2}=1.12\end{array}$} & $\begin{array}{l}P_{d I 2} \\
\text { (p.u.) } \\
0.08\end{array}$ & $\begin{array}{l}\mathbf{V}_{\mathbf{8 5}}=0.963 \angle-18.368 \\
\mathbf{V}_{\mathbf{8 8}}=0.99 \angle-19.710 \\
\mathbf{V}_{\mathbf{2 3 3}}=0.967 \angle-18.23\end{array}$ & $\begin{array}{l}V_{d I 1}=0.995 ; V_{d I 2}=0.9992 ; P_{d I R}=0.5826 ; I_{d I 1}= \\
0.5025 ; I_{d I 2}=0.05 ; I_{d R}=0.5526 ; \gamma_{I 1}=16.3001 ; \gamma_{I 2}= \\
21.7912 ; \alpha_{R}=15.7287 ; \cos \phi_{I 1}=0.9137 ; \cos \phi_{I 2}= \\
0.9212 ; \cos \phi_{R}=0.9096 ; \mathrm{NI}=14 ; \mathrm{CT}=93.294982 ;\end{array}$ \\
\hline & & & 0.1 & $\begin{array}{l}\mathbf{V}_{\mathbf{8 5}}=0.9635 \angle-18.36 \\
\mathbf{V}_{\mathbf{8 8}}=0.99 \angle-19.715 \\
\mathbf{V}_{\mathbf{2 3 3}}=0.9674 \angle-17.79\end{array}$ & $\begin{array}{l}V_{d I 1}=0.995 ; V_{d I 2}=0.999 ; P_{d I R}=0.6026 ; I_{d I 1}= \\
0.5025 ; I_{d I 2}=0.1001 ; I_{d R}=0.6026 ; \gamma_{I 1}=16.3001 ; \gamma_{I 2}= \\
21.3669 ; \alpha_{R}=15.133 ; \cos \phi_{I 1}=0.9137 ; \cos \phi_{I 2}= \\
0.922 ; \cos \phi_{R}=0.9105 ; \mathrm{NI}=15 ; \mathrm{CT}=95.894141 ;\end{array}$ \\
\hline & & & 0.15 & $\begin{array}{l}\mathbf{V}_{\mathbf{8 5}}=0.9611 \angle-18.314 \\
\mathbf{V}_{\mathbf{8 8}}=0.99 \angle-19.7325 \\
\mathbf{V}_{\mathbf{2 3 3}}=0.9647 \angle-17.30\end{array}$ & $\begin{array}{l}V_{d I 1}=0.995 ; V_{d I 2}=0.9985 ; P_{d I R}=0.6528 ; I_{d I 1}= \\
0.5025 ; I_{d I 2}=0.1502 ; I_{d R}=0.6528 ; \gamma_{I 1}=16.3001 ; \gamma_{I 2}= \\
20.2677 ; \alpha_{R}=13.5279 ; \cos \phi_{I 1}=0.9137 ; \cos \phi_{I 2}= \\
0.9242 ; \cos \phi_{R}=0.9127 ; \mathrm{NI}=15 ; \mathrm{CT}=93.322688 ;\end{array}$ \\
\hline & & & 0.2 & $\begin{array}{l}\mathbf{V}_{\mathbf{8 5}}=0.9588 \angle-18.268 \\
\mathbf{V}_{\mathbf{8 8}}=0.99 \angle-19.7537 \\
\mathbf{V}_{\mathbf{2 3 3}}=0.962 \angle-16.815\end{array}$ & $\begin{array}{l}V_{d I 1}=0.995 ; V_{d I 2}=0.998 ; P_{d I R}=0.7029 ; I_{d I 1}= \\
0.5025 ; I_{d I 2}=0.2004 ; I_{d R}=0.7029 ; \gamma_{I 1}=16.3001 ; \gamma_{I 2}= \\
19.1062 ; \alpha_{R}=11.6988 ; \cos \phi_{I 1}=0.9137 ; \cos \phi_{I 2}= \\
0.9263 ; \cos \phi_{R}=0.9149 ; \mathrm{NI}=16 ; \mathrm{CT}=101.913689 ;\end{array}$ \\
\hline & & & 0.25 & $\begin{array}{l}\mathbf{V}_{\mathbf{8 5}}=0.9564 \angle-18.228 \\
\mathbf{V}_{\mathbf{8 8}}=0.99 \angle-19.7786 \\
\mathbf{V}_{\mathbf{2 3 3}}=0.9593 \angle-16.32\end{array}$ & $\begin{array}{l}V_{d I 1}=0.995 ; V_{d I 2}=0.9975 ; P_{d R}=0.7532 ; I_{d I 1}= \\
0.5025 ; I_{d I 2}=0.2506 ; I_{d R}=0.7532 ; \gamma_{I 1}=16.3001 ; \gamma_{I 2}= \\
17.8704 ; \alpha_{R}=9.522 ; \cos \phi_{I 1}=0.9137 ; \cos \phi_{I 2}= \\
0.9284 ; \cos \phi_{R}=0.9171 ; \mathrm{NI}=17 ; \mathrm{CT}=135.807279 ;\end{array}$ \\
\hline & & & 0.3 & $\begin{array}{l}\mathbf{V}_{\mathbf{8 8}}=0.99 \angle-19.8072 \\
\mathbf{V}_{233}=0.9566 \angle-15.84 \\
\mathbf{V}_{\mathbf{8 8}}=0.99 \angle-19.8072\end{array}$ & $\begin{array}{l}V_{d I 1}=0.995 ; V_{d I 2}=0.997 ; P_{d I R}=0.8034 ; I_{d I 1}= \\
0.5025 ; I_{d I 2}=0.3009 ; I_{d R}=0.8034 ; \gamma_{I 1}=16.3001 ; \gamma_{I 2}= \\
16.544 ; \alpha_{R}=6.602 ; \cos \phi_{I 1}=0.9137 ; \cos \phi_{I 2}= \\
0.9305 ; \cos \phi_{R}=0.9194 ; \mathrm{NI}=19 ; \mathrm{CT}=118.803820\end{array}$ \\
\hline
\end{tabular}

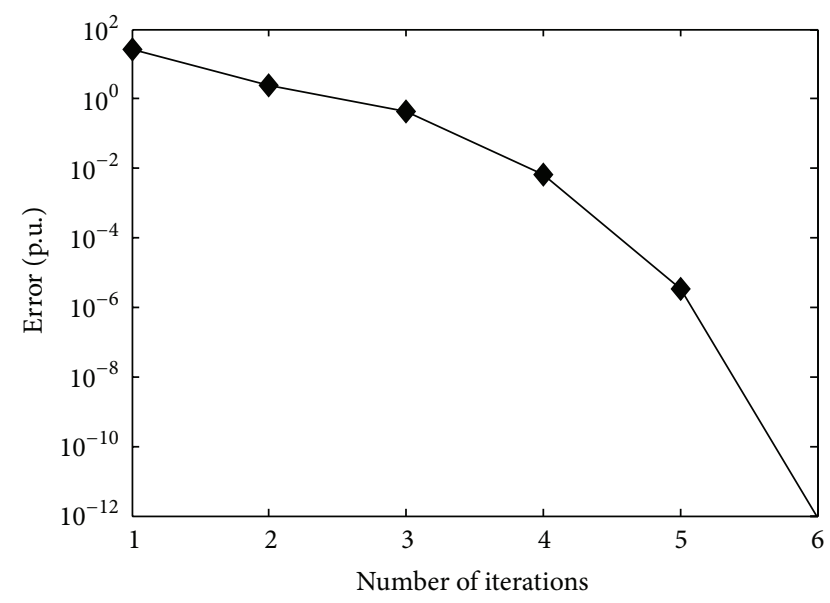

FIGURE 9: Convergence characteristics for case study IX of Table 4 with control strategy 9.

During the numerous studies carried out in the above AC-DC system, it was also observed that, for a particular control strategy adopted, the power-flow convergence pattern is also affected by the values of the controlled variables corresponding to that strategy. Now, the value of the DC link power transfer is one of the most important control variables. Hence, two more case studies were conducted to observe the effect of the variation of the DC link power transfer on the power-flow convergence pattern. Since the poorest convergence pattern is observed with control strategy 5 (Table 3), hence, for both of the case studies, this strategy is adopted. The details of the case studies are given below.

Case Study X. In this case study, the power transfer over the first DC link " $P_{d I 1}$ " is maintained to a constant value of 0.5 p.u. On the other hand, the power transfer over the second DC link " $P_{d I 2}$ " is gradually increased from 0.08 p.u. to 0.3 p.u. The value of the specified quantities is shown in columns 3-4 of Table 5 .

The power-flow solutions are detailed in columns 5-6 of Table 5. The variation of "NI" with active power in the second DC link is shown in Figure 4. From Figure 10, it is observed that "NI" increases as " $P_{d I 2}$ " is increased.

Case Study XI. In this case study, the power transfer over the first DC link " $P_{d I 1}$ " is gradually increased from 0.1 p.u. to 0.28 p.u. while maintaining the power transfer over the second one $\left(P_{d I 2}\right)$ to a constant value of $0.2 \mathrm{p}$.u. The specified quantities and the power-flow solutions are shown in columns 3-4 and 5-6 of Table 6, respectively. The variation of "NI" with active power in the first DC link is shown in Figure 11. From Figure 11, it is again observed that "NI" increases as " $P_{d I 1}$ " is increased.

\section{Conclusions}

For power-flow solution of an integrated AC-DC system, control specifications adopted for the system bridge the 
TABLE 6: Study of power-flow convergence pattern with active power in the first DC link.

\begin{tabular}{|c|c|c|c|c|c|}
\hline \multicolumn{2}{|c|}{ HVDC links } & \multirow{2}{*}{\multicolumn{2}{|c|}{$\begin{array}{l}\text { HVDC link specification } \\
\text { Control strategy } 5\end{array}$}} & \multirow{2}{*}{\multicolumn{2}{|c|}{$\begin{array}{l}\text { Power-flow solutions } \\
\text { HVDC variables }\end{array}$}} \\
\hline $\begin{array}{l}\text { Rectifier } \\
\text { bus }\end{array}$ & $\begin{array}{c}\text { Inverter } \\
\text { buses }\end{array}$ & & & & \\
\hline \multirow{5}{*}{85} & \multirow{5}{*}{88,233} & \multirow{5}{*}{$\begin{array}{l}P_{d I 2}=0.2 \\
\text { (p.u.) } \\
V_{d R}=1 \text { (p.u.) } \\
a_{R}=1.08 \\
a_{I 1}=1.1 \\
a_{I 2}=1.1\end{array}$} & $\begin{array}{c}P_{d I 1} \\
(\text { p.u. }) \\
0.1\end{array}$ & $\begin{array}{l}\mathbf{V}_{\mathbf{8 5}}=0.9831 \angle-17.3494 \\
\mathbf{V}_{\mathbf{8 8}}=0.99 \angle-20.2874 \\
\mathbf{V}_{\mathbf{2 3 3}}=0.9858 \angle-15.9583\end{array}$ & $\begin{array}{l}V_{d I 1}=0.999 ; V_{d I 2}=0.998 ; P_{d I R}=0.3005 ; I_{d I 1}= \\
0.1001 ; I_{d I 2}=0.2004 ; I_{d R}=0.3005 ; \gamma_{I 1}=22.0973 ; \gamma_{I 2}= \\
20.1488 ; \alpha_{R}=14.0408 ; \cos \phi_{I 1}=0.9174 ; \cos \phi_{I 2}= \\
0.9203 ; \cos \phi_{R}=0.9418 ; \mathrm{NI}=14 ; \mathrm{CT}=87.437434 ;\end{array}$ \\
\hline & & & 0.15 & $\begin{array}{l}\mathbf{V}_{\mathbf{8 5}}=0.9808 \angle-17.4693 \\
\mathbf{V}_{\mathbf{8 8}}=0.99 \angle-20.2093 \\
\mathbf{V}_{\mathbf{2 3 3}}=0.9836 \angle-16.075\end{array}$ & $\begin{array}{l}V_{d I 1}=0.9985 ; V_{d I 2}=0.998 ; P_{d I R}=0.3506 ; I_{d I 1}= \\
0.1502 ; I_{d I 2}=0.2004 ; I_{d R}=0.3506 ; \gamma_{I 1}=21.4575 ; \gamma_{I 2}= \\
19.801 ; \alpha_{R}=12.2691 ; \cos \phi_{I 1}=0.9169 ; \cos \phi_{I 2}= \\
0.9224 ; \cos \phi_{R}=0.9441 ; \mathrm{NI}=14 ; \mathrm{CT}=87.093402 ;\end{array}$ \\
\hline & & & 0.2 & $\begin{array}{l}\mathbf{V}_{\mathbf{8 5}}=0.9785 \angle-17.5935 \\
\mathbf{V}_{\mathbf{8 8}}=0.99 \angle-20.1333 \\
\mathbf{V}_{\mathbf{2 3 3}}=0.9815 \angle-16.196\end{array}$ & $\begin{array}{l}V_{d I 1}=0.998 ; V_{d I 2}=0.998 ; P_{d I R}=0.4008 ; I_{d I 1}= \\
0.2004 ; I_{d I 2}=0.2004 ; I_{d R}=0.4008 ; \gamma_{I 1}=20.7986 ; \gamma_{I 2}= \\
19.4495 ; \alpha_{R}=10.1946 ; \cos \phi_{I 1}=0.9164 ; \cos \phi_{I 2}= \\
0.9244 ; \cos \phi_{R}=0.9463 ; \mathrm{NI}=15 ; \mathrm{CT}=92.089820 ;\end{array}$ \\
\hline & & & 0.25 & $\begin{array}{l}\mathbf{V}_{\mathbf{8 5}}=0.9762 \angle-17.7218 \\
\mathbf{V}_{\mathbf{8 8}}=0.99 \angle-20.0592 \\
\mathbf{V}_{\mathbf{2 3 3}}=0.9794 \angle-16.3212\end{array}$ & $\begin{array}{l}V_{d I 1}=0.9975 ; V_{d I 2}=0.998 ; P_{d I R}=0.4510 ; I_{d I 1}= \\
0.5025 ; I_{d I 2}=0.2004 ; I_{d R}=0.4510 ; \gamma_{I 1}=20.1179 ; \gamma_{I 2}= \\
19.0945 ; \alpha_{R}=7.5728 ; \cos \phi_{I 1}=0.916 ; \cos \phi_{I 2}= \\
0.9246 ; \cos \phi_{R}=0.9485 ; \mathrm{NI}=15 ; \mathrm{CT}=91.472996 ;\end{array}$ \\
\hline & & & 0.28 & $\begin{array}{l}\mathbf{V}_{\mathbf{8 5}}=0.9748 \angle-17.8008 \\
\mathbf{V}_{\mathbf{8 8}}=0.99 \angle-20.0158 \\
\mathbf{V}_{\mathbf{2 3 3}}=0.978 \angle-16.3983\end{array}$ & $\begin{array}{l}V_{d I 1}=0.9972 ; V_{d I 2}=0.998 ; P_{d R}=0.4812 ; I_{d I 1}= \\
0.2808 ; I_{d I 2}=0.2004 ; I_{d R}=0.4812 ; \gamma_{I 1}=19.6985 ; \gamma_{I 2}= \\
18.8797 ; \alpha_{R}=5.4231 ; \cos \phi_{I 1}=0.9157 ; \cos \phi_{I 2}= \\
0.9276 ; \cos \phi_{R}=0.9498 ; \mathrm{NI}=16 ; \mathrm{CT}=99.869132\end{array}$ \\
\hline
\end{tabular}

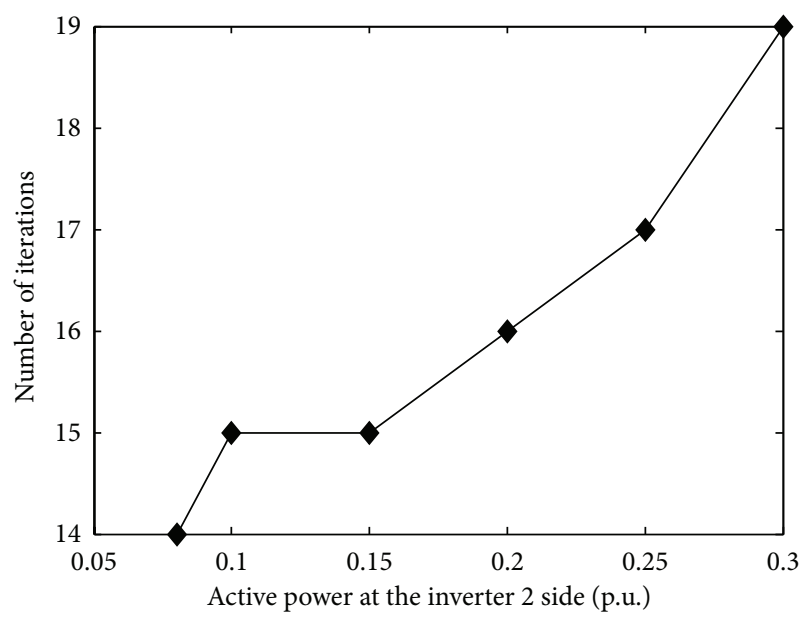

FIGURE 10: Variation of "NI" with active power in second DC link.

gap between the number of independent equations and the number of unknown quantities. Depending on the application, several combinations of valid control specifications are possible. Each combination of a set of valid control specifications comprises a control strategy. It is observed that the power-flow convergence is strongly affected by the control strategy adopted. This work investigates the mechanism by which different control strategies affect the convergence of the iterative process. It is observed that, for a majority of the possible control strategies, the equivalent power injections at the converter terminal buses are independent of the NR iterative loop. However, for others, the equivalent reactive power injections need to be computed in every NR iteration. This

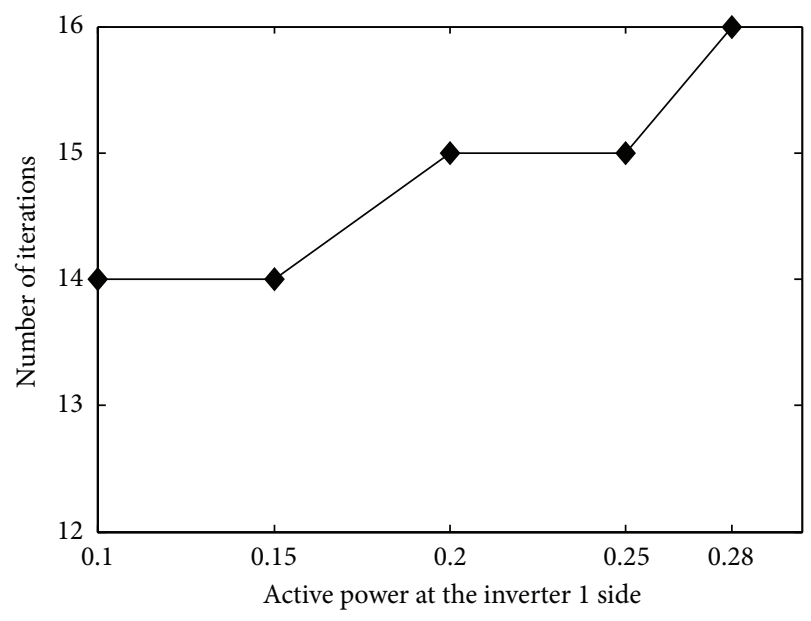

FIGURE 11: Variation of "NI" with active power in first DC link.

affects the convergence of the algorithm. This is validated by multiple case studies with application of nine different control strategies on a three-terminal DC network incorporated in the IEEE 300-bus test system.

From the case studies, it was observed that the powerflow convergence pattern for integrated AC-DC systems depends upon a number of factors. Firstly, it depends on the control strategy adopted for the DC link. Secondly, for a particular control strategy adopted, it depends upon the values of the electrical quantities specified in the control strategy. In addition, it also depends upon the location of the DC link, that is, the system buses between which the link is incorporated. 
TABLE 7: Steps to compute active and reactive power injections in control strategies 1 and 5.

(a)

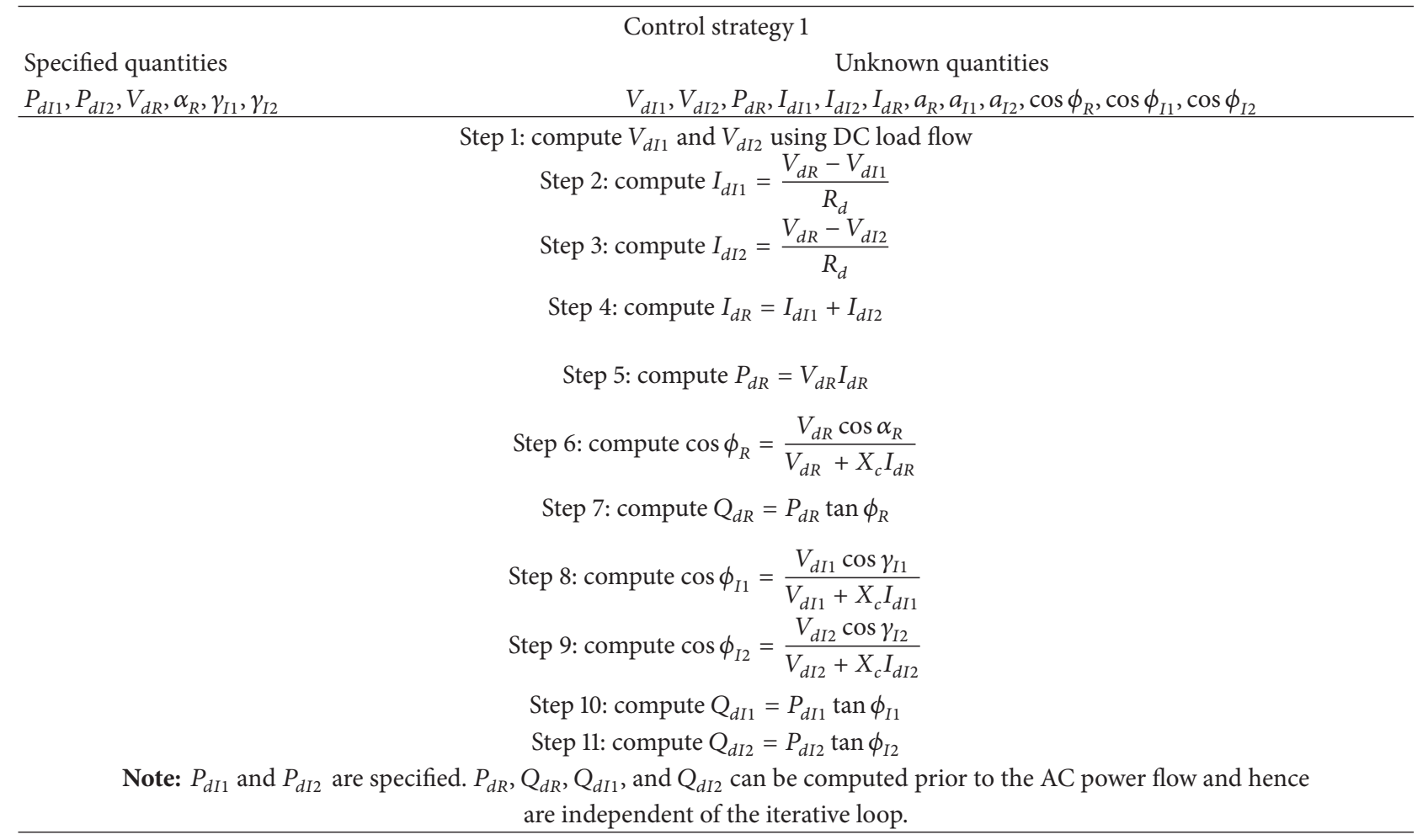

(b)

Specified quantities

Control strategy 5

Unknown quantities

$\underline{P_{d I 1}, P_{d I 2}, V_{d R}, a_{R}, a_{I 1}, a_{I 2}}$

$V_{d I 1}, V_{d I 2}, P_{d R}, I_{d I 1}, I_{d I 2}, I_{d R}, \alpha_{R}, \gamma_{I 1}, \gamma_{I 2}, \cos \phi_{R}, \cos \phi_{I 1}, \cos \phi_{I 2}$

Step 1: compute $V_{d I 1}$ and $V_{d I 2}$ using DC load flow

Step 2: compute $I_{d I 1}=\frac{V_{d R}-V_{d I 1}}{R_{d}}$

Step 3: compute $I_{d I 2}=\frac{V_{d R}-V_{d I 2}}{R_{d}}$

Step 4: compute $I_{d R}=I_{d I 1}+I_{d I 2}$

Step 5: compute $P_{d R}=V_{d R} I_{d R}$

Step 6: compute $\cos \phi_{R}=\frac{V_{d R}}{a_{R} V_{i}}$

Note 1: $V_{i}$ is an AC power-flow variable and is updated in every iteration. Hence, $\cos \phi_{R}$ changes in every iteration.

$$
\begin{aligned}
& \text { Step 7: compute } Q_{d R}=P_{d R} \tan \phi_{R} \\
& \text { Step 8: compute } \cos \phi_{I 1}=\frac{V_{d I 1}}{a_{I 1} V_{j}} \\
& \text { Step 9: compute } \cos \phi_{I 2}=\frac{V_{d I 2}}{a_{I 2} V_{k}}
\end{aligned}
$$

Note 2: $V_{j}$ and $V_{k}$ are also AC power-flow variables and are updated in every iteration, along with $\cos \phi_{I 1}$ and $\cos \phi_{I 2}$.

$$
\begin{aligned}
& \text { Step 10: compute } Q_{d I 1}=P_{d I 1} \tan \phi_{I 1} \\
& \text { Step 11: compute } Q_{d I 2}=P_{d I 2} \tan \phi_{I 2}
\end{aligned}
$$

Note 3: $P_{d I 1}$ and $P_{d I 2}$ are specified. $P_{d R}$ can be computed prior to the AC power flow. However, $Q_{d R}, Q_{d I 1}$, and $Q_{d I 2}$ depend upon $\phi_{R}, \phi_{I 1}$, and $\phi_{I 2}$, respectively, and need to be updated in every iteration. 
The above research work could be further extended by investigating and comparing the effects of power-flow algorithms other than the sequential method. The effect of power flow based on soft computing techniques on the convergence pattern can be investigated in light of different control methodologies and computation platforms.

\section{Appendices}

\section{A. Selection of Base Values for the DC System}

Consider

$$
\begin{aligned}
V_{\text {ac base }}=V(\text { line to line rms voltage }), \\
I_{\text {ac base }}=\frac{S_{\text {base }}}{\sqrt{3} V_{\text {ac base }}} \\
Z_{\text {ac base }}=\frac{V_{\text {ac base }}}{\sqrt{3} I_{\text {ac base }}} .
\end{aligned}
$$

\section{B. Computation of Active and Reactive Power Injections in Different Control Strategies}

As already explained in Section 4, for solving the AC power flow, the equivalent active and reactive power injections at the AC terminal buses connected to the converters need to be computed. The methods involved in the computation of the power injections for different control strategies are all different. However, they can be broadly categorized into two distinct ones. While in the first one the power injections are independent of the AC power flow, in the second one, they are dependent on the iterative process. Control strategies 1, 2, 3, 4 , and 9 belong to the former category while control strategies $5,6,7$, and 8 belong to the latter. The detailed steps involved in the computation of the power injections for control strategies 1 and 5 are shown in Table 7.

From Table 7, it can be observed that the active power injections can be computed prior to the AC power flow. It is also observed that, in control strategy 1, the quantities $\phi_{R}$, $\phi_{I 1}$, and $\phi_{I 2}$ and hence the reactive power injections $Q_{d R}$, $Q_{d I 1}$, and $Q_{d I 2}$ can be computed prior to the AC power flow by manipulation of the specified variables. On the other hand, in control strategy 5 , they are dependent on the AC powerflow variables and thus need to be updated in every iteration.

The steps corresponding to the other control strategies can be detailed in a similar manner and are not shown due to limitations of space.

\section{List of Symbols}

$$
\begin{aligned}
& S_{\text {base }} \text { : } \\
& V_{\text {ac base }}, I_{\text {ac base }} \text {, and } Z_{\text {ac base }} \text { : AC base voltage, AC base } \\
& \text { current, and AC base } \\
& \text { impedance, respectively } \\
& V_{\mathrm{dc} \text { base }}, I_{\mathrm{dc} \text { base }} \text {, and } Z_{\mathrm{dc} \text { base }} \text { : DC base voltage, DC base } \\
& \text { current, and DC base } \\
& \text { impedance, respectively } \\
& n_{b}: \\
& X_{c} \text { : } \\
& \text { Number of bridges } \\
& \text { Commutating reactance }
\end{aligned}
$$

$V_{d}, I_{d}: \quad$ DC voltage and current, respectively

$\phi_{R}$ : $\quad$ Power factor angle at the rectifier end

$\phi_{I 1}, \phi_{I 2}: \quad$ Power factor angles at inverter 1 and inverter 2 ends, respectively

$\alpha_{R}: \quad$ Firing angle of the rectifier

$\gamma_{I 1}, \gamma_{I 2}$ : Extinction angles of inverter 1 and inverter 2, respectively

$V_{d R}: \quad$ DC voltage at the rectifier end

$V_{d I 1}, V_{d I 2}$ : DC voltages at inverter 1 and inverter 2 ends, respectively

$a_{R}$ : Tap ratio of the converter transformer at the rectifier end

$a_{I 1}, a_{I 2}$ : Tap ratios of the converter transformers at

inverter 1 and inverter 2 ends, respectively

$R_{d}: \quad$ DC link resistance

$V_{i} \angle \theta_{i}$ : $\quad$ AC bus voltage magnitude (rms) and phase angle at $i$ th bus

$V_{j} \angle \theta_{j}: \quad$ AC bus voltage magnitude (rms) and phase angle at $j$ th bus

$V_{k} \angle \theta_{k}: \quad$ AC bus voltage magnitude (rms) and phase angle at $k$ th bus

$V_{d o R}: \quad \quad \quad \quad$ No load direct voltage at the rectifier side

$V_{d o I 1}, V_{d o I 2}$ : No load direct voltages at inverter 1 and inverter 2 ends, respectively

$P_{D i}, Q_{D i}: \quad$ Active and reactive power demand at bus " $i$," respectively

$P_{i}, Q_{i}: \quad$ Net active and reactive power injection at bus " $i$," respectively

$P_{d R}, Q_{d R}: \quad$ Equivalent active and reactive power injection of the rectifier, respectively

$P_{d I 1}, P_{d I 2}: \quad$ Equivalent active power injections of inverter 1 and inverter 2 , respectively

$Q_{d I 1}, Q_{d I 2}$ : Equivalent reactive power injections of inverter 1 and inverter 2 , respectively.

\section{Conflict of Interests}

The authors declare that there is no conflict of interests regarding the publication of this paper.

\section{References}

[1] J. Arrillaga and N. R. Watson, Computer Modelling of Electrical Power Systems, John Wiley \& Sons, Chichester, UK, 2nd edition, 2001.

[2] P. Kundur, Power System Stability and Control, Tata McGrawHill Publishing, 2007.

[3] X. F. Wang, Y. H. Song, and M. Irving, Modern Power Systems Analysis, Springer, Berlin, Germany, 2008.

[4] K. R. Padiyar, HVDC Power Transmission Systems, New Age International Publishers, 2nd edition, 2012.

[5] T. Smed, G. Andersson, G. B. Sheble, and L. L. Grigsby, "A new approach to AC/DC power flow," IEEE Transactions on Power Systems, vol. 6, no. 3, pp. 1238-1244, 1991.

[6] J. Reeve, G. Fahmy, and B. Stott, "Versatile load flow method for multi terminal HVDC systems," IEEE Transactions on Power Apparatus and Systems, vol. 96, no. 3, pp. 925-933, 1977. 
[7] M. E. El-Hawary and S. T. Ibrahim, "A new approach to AC-DC load flow analysis," Electric Power Systems Research, vol. 33, no. 3, pp. 193-200, 1995.

[8] K. R. Padiyar and V. Kalyanaraman, "Power flow analysis in MTDC-AC systems-A new approach," Electric Machines and Power Systems, vol. 23, no. 1, pp. 37-54, 1995.

[9] Y. K. Fan, D. Niebur, C. O. Nwankpa, H. Kwanty, and R. Fischl, "Multiple power flow solutions of small integrated $\mathrm{AC} / \mathrm{DC}$ power systems," in Proceedings of the IEEE International Symposium on Circuits and Systems (ISCAS '00), vol. 2, pp. 224227, Geneva, Switzerland, 2000.

[10] C. Liu, B. Zhang, Y. Hou, F. F. Wu, and Y. Liu, "An improved approach for AC-DC power flow calculation with multi-infeed DC systems," IEEE Transactions on Power Systems, vol. 26, no. 2, pp. 862-869, 2011.

[11] C. Liu, A. Bose, and Y. Hou, "Discussion of the solvability of HVDC systems power flow with a sequential method," Electric Power Systems Research, vol. 92, pp. 155-161, 2012.

[12] S. Messalti, S. Belkhiat, S. Saadate, and D. Flieller, "A new approach for load flow analysis of integrated AC-DC power systems using sequential modified Gauss-Seidel methods," European Transactions on Electrical Power, vol. 22, no. 4, pp. 421-432, 2012.

[13] U. Kiliç and K. Ayan, "Optimizing power flow of AC-DC power systems using artificial bee colony algorithm," International Journal of Electrical Power \& Energy Systems, vol. 53, no. 1, pp. 592-602, 2013.

[14] Y. Sun, G. Zhang, W. Xu, and J. G. Mayordomo, "A harmonically coupled admittance matrix model for AC/DC converters," IEEE Transactions on Power Systems, vol. 22, no. 4, pp. 1574-1582, 2007.

[15] J. Yu, W. Yan, W. Li, C. Y. Chung, and K. P. Wong, "An unfixed piecewise-optimal reactive power-flow model and its algorithm for AC-DC systems," IEEE Transactions on Power Systems, vol. 23, no. 1, pp. 170-176, 2008.

[16] R. Wiget and G. Andersson, "DC optimal power flow including HVDC grids," in Proceedings of the IEEE Electrical Power and Energy Conference (EPEC '13), pp. 1-6, August 2013.

[17] D. L. H. Aik and G. Andersson, "Analysis of voltage and power interactions in multi-infeed HVDC systems," IEEE Transactions on Power Delivery, vol. 28, no. 2, pp. 816-824, 2013.

[18] U. Kiliç, K. Ayan, and U. Arifoğlu, "Optimizing reactive power flow of HVDC systems using genetic algorithm," International Journal of Electrical Power and Energy Systems, vol. 55, pp. 1-12, 2014.

[19] M. J. Carrizosa, F. D. Navas, G. Damm, and F. LamnabhiLagarrigue, "Optimal power flow in multi-terminal HVDC grids with offshore wind farms and storage devices," International Journal of Electrical Power \& Energy Systems, vol. 65, pp. 291-298, 2015.

[20] http://www.ee.washington.edu/research/pstca/. 

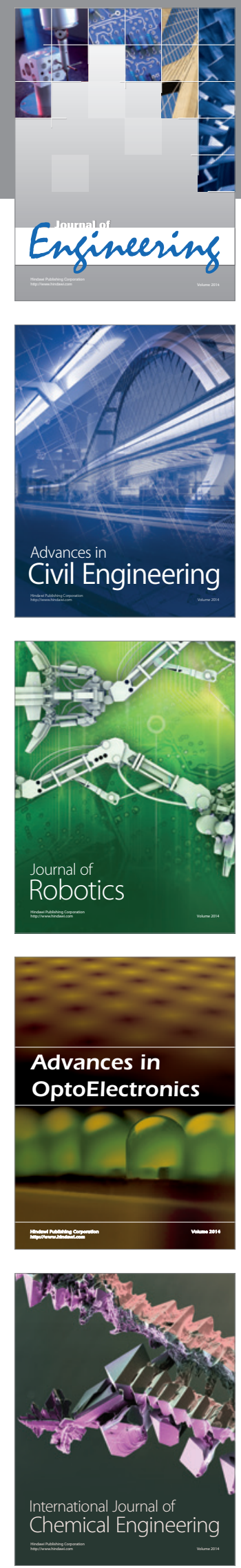

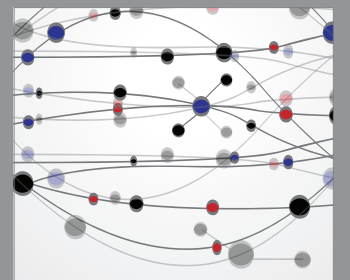

The Scientific World Journal
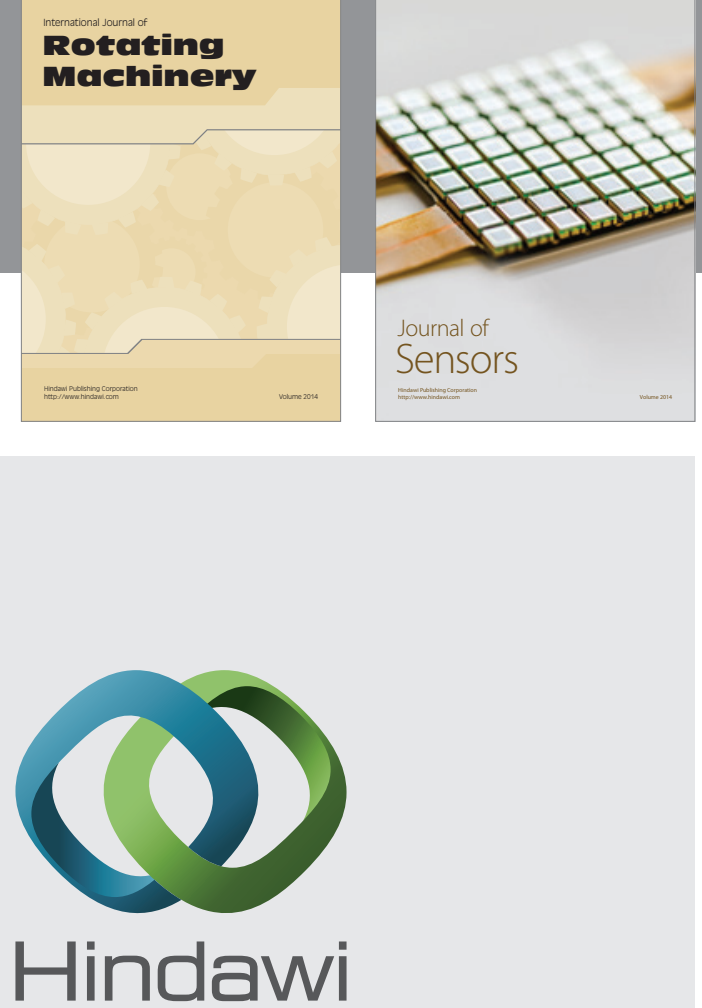

Submit your manuscripts at http://www.hindawi.com
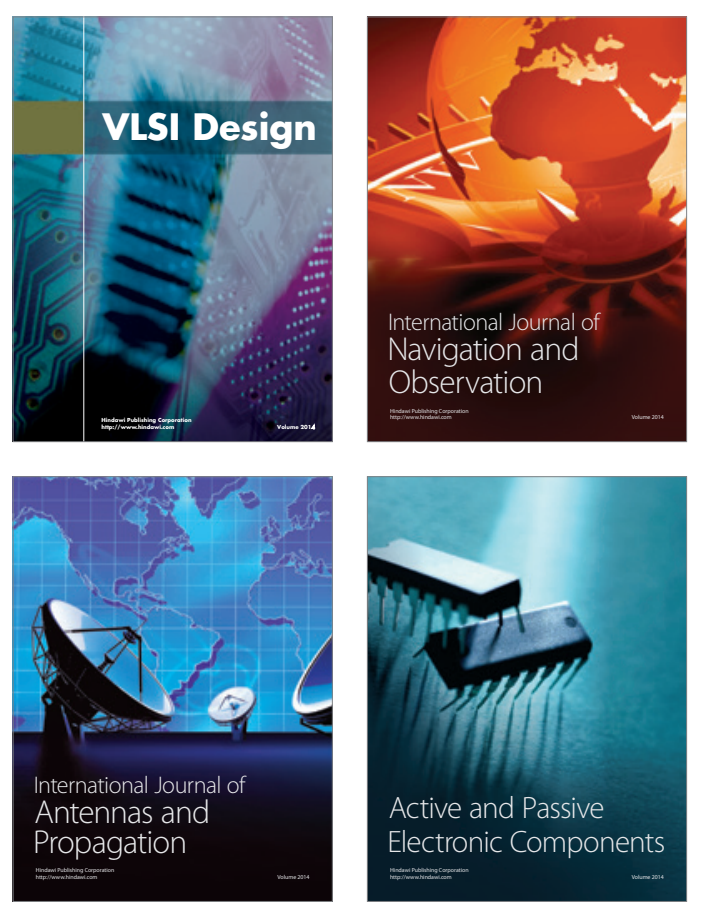
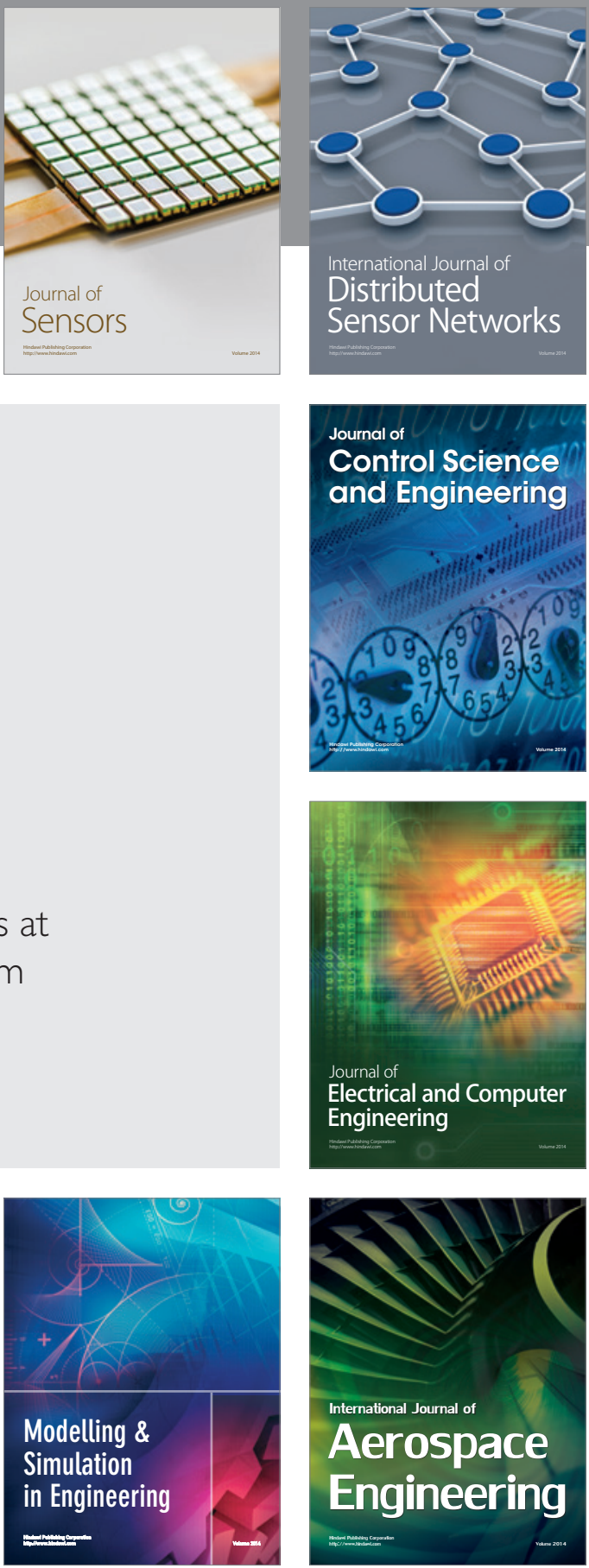

Journal of

Control Science

and Engineering
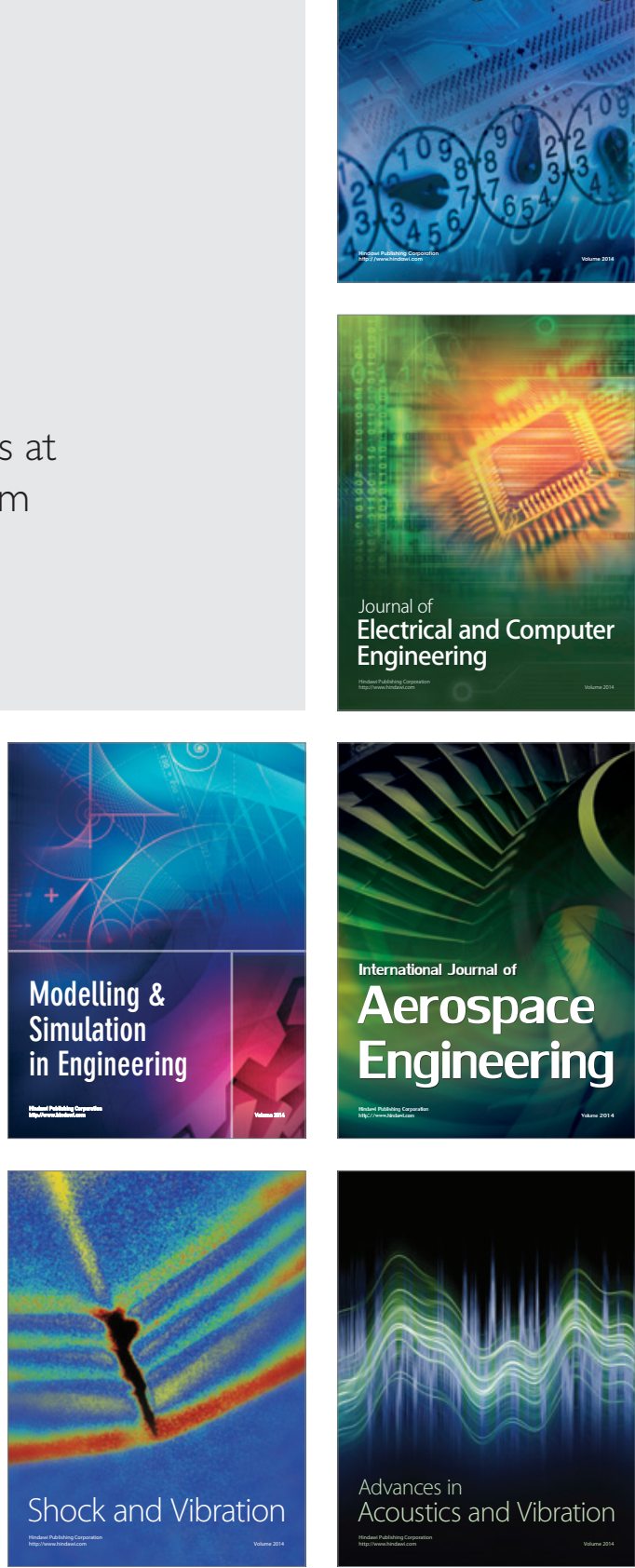